2003s-44

\title{
Education and Smoking: Were Vietnam War Draft Avoiders Also More Likely to Avoid Smoking?
}

\author{
Franque Grimard, Daniel Parent
}

\section{Série Scientifique \\ Scientific Series}

\section{Montréal \\ Août 2003}

(C) 2003 Franque Grimard, Daniel Parent. Tous droits réservés. All rights reserved. Reproduction partielle permise avec citation du document source, incluant la notice (C).

Short sections may be quoted without explicit permission, if full credit, including ( $)$ notice, is given to the source.
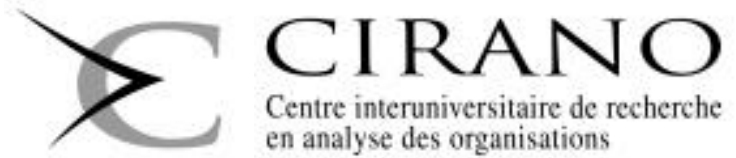

en analyse des organisations 


\section{CIRANO}

Le CIRANO est un organisme sans but lucratif constitué en vertu de la Loi des compagnies du Québec. Le financement de son infrastructure et de ses activités de recherche provient des cotisations de ses organisationsmembres, d'une subvention d'infrastructure du ministère de la Recherche, de la Science et de la Technologie, de même que des subventions et mandats obtenus par ses équipes de recherche.

CIRANO is a private non-profit organization incorporated under the Québec Companies Act. Its infrastructure and research activities are funded through fees paid by member organizations, an infrastructure grant from the Ministère de la Recherche, de la Science et de la Technologie, and grants and research mandates obtained by its research teams.

Les organisations-partenaires / The Partner Organizations

PARTENAire Majeur

. Ministère du développement économique et régional [MDER]

PARTENAIRES

. Alcan inc.

. Axa Canada

. Banque du Canada

. Banque Laurentienne du Canada

. Banque Nationale du Canada

. Banque Royale du Canada

. Bell Canada

. Bombardier

. Bourse de Montréal

. Développement des ressources humaines Canada [DRHC]

. Fédération des caisses Desjardins du Québec

- Gaz Métropolitain

. Hydro-Québec

. Industrie Canada

. Ministère des Finances [MF]

. Pratt \& Whitney Canada Inc.

. Raymond Chabot Grant Thornton

. Ville de Montréal

. École Polytechnique de Montréal

. HEC Montréal

. Université Concordia

. Université de Montréal

. Université du Québec à Montréal

. Université Laval

. Université McGill

AsSOCIÉ À :

. Institut de Finance Mathématique de Montréal (IFM ${ }^{2}$ )

. Laboratoires universitaires Bell Canada

. Réseau de calcul et de modélisation mathématique $\left[\mathrm{RCM}^{2}\right]$

. Réseau de centres d'excellence MITACS (Les mathématiques des technologies de l'information et des systèmes complexes)

Les cahiers de la série scientifique (CS) visent à rendre accessibles des résultats de recherche effectuée au CIRANO afin de susciter échanges et commentaires. Ces cahiers sont écrits dans le style des publications scientifiques. Les idées et les opinions émises sont sous l'unique responsabilité des auteurs et ne représentent pas nécessairement les positions du CIRANO ou de ses partenaires.

This paper presents research carried out at CIRANO and aims at encouraging discussion and comment. The observations and viewpoints expressed are the sole responsibility of the authors. They do not necessarily represent positions of CIRANO or its partners.

ISSN 1198-8177 


\title{
Education and Smoking: Were Vietnam War Draft Avoiders Also More Likely to Avoid Smoking?
}

\author{
Franque Grimard", Daniel Parent
}

\begin{abstract}
Résumé / Abstract
Nous utilisons la propension des hommes nés aux États-Unis dans les années '40 à vouloir éviter d'être recrutés pour participer à la guerre du Vietnam en poursuivant leurs études postsecondaires, tel que documenté dans Card et Lemieux (2002), afin d'inférer le lien causal entre l'éducation et le tabagisme. Nos résultats indiquent que les individus ayant davantage d'éducation sont nettement moins susceptibles de fumer la cigarette au moment de l'entrevue, particulièrement en ce qui concerne le fait de fumer régulièrement. Toutefois, l'impact de l'éducation sur le fait de cesser de fumer semble plutôt modeste. D'une part, il n'y a pas d'évidence très forte à l'effet qu'une augmentation exogène de l'éducation accroisse la probabilité de ne pas fumer au moment de l'entrevue, conditionnellement au fait d'avoir fumé régulièrement à un moment donnée dans sa vie. D'autre part, parmi les anciens fumeurs réguliers, nous trouvons que le nombre d'années passées à fumer est moindre pour ceux qui ont davantage d'éducation.
\end{abstract}

Mots clés : tabagisme, éducation, guerre du Vietnam, variables instrumentales.

We use the Vietnam War draft avoidance behavior documented by Card et Lemieux (2002) as a quasi-natural experiment to infer causation from education to smoking and find strong evidence that education, whether it be measured in years of completed schooling or in educational attainment categories, reduces the probability of smoking at the time of the interview, more particularly the probability of smoking regularly. Interestingly, however, while we find that more education substantially increases the probability of never smoking, our other main finding is suggestive that increased education has a limited impact on smoking cessation behavior. On the one hand there is little evidence that it helps to increase the probability of not smoking regularly at the time of the interview, conditional on having smoked regularly at any time. However, among former regular smokers, those with more education have significantly shorter smoking careers.

Keywords: cigarette smoking, education, Vietnam War, draft avoidance, instrumental variables.

\footnotetext{
* Department of Economics, McGill University

$\dagger$ Department of Economics, McGill University, CIRANO, Groupe ressources humaines.
} 


\section{Introduction}

Since the release of the 1964 Surgeon General Report on smoking and health, people have been increasingly aware of the dangers related to tobacco consumption. For instance, smoking prevalence among men fell from 52 percent in 1965 to 25.7 percent in 2000 (U.S. Department of Health and Human Services 2000, 2002). Yet, despite the expansion of scientific knowledge about the health hazards of smoking, the various public health campaigns waged by governments, and the numerous regulatory measures against tobacco, there is still a sizeable fraction of the population smoking at least occasionally. Given that people typically start smoking regularly rather early in life and that the addictive nature of cigarette smoking makes it difficult for many to subsequently stop, any policy that results in more people never picking up the habit would have significant consequences in terms of public health.

One such factor that is associated with a much lower prevalence of smoking is education: economists have long observed a positive relationship between education and health levels in many instances (Grossman (1972), Sander (1995), Chaloupka (1991)). Indeed, this link between education and health is not specific to tobacco consumption. Education and health have long been recognized as important factors in human capital accumulation associated with a rise of living standards of individuals throughout the world. ${ }^{1}$

Yet, much like in the economics of education literature, where the strong positive correlation between earnings and educational attainment has been under intense scrutiny over the last two decades, there is some disagreement as to whether the relationship between education and health outcomes in general, and smoking in particular, is causal or not. There is a body of the literature claiming that the correlation is due to other factors. In particular, Fuchs (1982) and Farrell and Fuchs (1982) have argued that the missing element is the rate of time preference: those with a low discount rate will tend to invest more in health and in education. Others have minimized the importance of the discount factor. For instance, based on their

\footnotetext{
${ }^{1}$ Both health and education can be seen as representing different forms of human capital that may allow individuals to raise their standard of living. Furthermore, each type of human capital investment may be seen as interacting with the other: greater health capital may improve the return to investment in education, as a longer life raises the return to investment in education or that better health may lower the rate of depreciation of education capital. Similarly, greater education capital may raise the return to investment in health, because many health programs rely on knowledge/skills learned where more educated individuals can potentially process the health risk information better.
} 
assessment of the literature, Grossman and Kaestner (1997) conclude that the relationship between smoking and health outcomes does seem to reflect a causal mechanism. Finally, Becker and Mulligan (1997) bridge the two views by presenting an innovative theoretical model of the determination of the discount factor. Such a model allows for reverse causation between discount rates and health investments. Given the difficulty in observing both of these elements separately, identifying the exact links between discount factors and health investment separately is an arduous task.

This paper does not attempt to perform this role. Rather, we pursue the more modest goal of trying to identify a causal relationship from education to cigarette smoking. Indeed, given that Grossman (2000) recognizes "the difficulties of establishing causality in the social sciences where natural experiments rarely can be performed", we analyze a presumably unforeseen consequence of a specific event in the recent history of the United States. With data from the Current Population Survey Tobacco Supplements, we use the Vietnam War draft avoidance behavior documented by Card and Lemieux (2002) as a quasi-natural experiment to infer causation from education to smoking. We find strong evidence that education, whether it be measured in years of completed schooling or in educational attainment categories, reduces the probability of smoking at the time of the interview, more particularly the probability of smoking regularly. Interestingly, however, while we find that more education substantially increases the probability of never smoking, our other main finding is suggestive that increased education has a limited impact on smoking cessation behavior. On the one hand there is little evidence that it helps to increase the probability of not smoking regularly at the time of the interview, conditional on having smoked regularly at any time. However, among former regular smokers, those with more education have significantly shorter smoking careers.

Our identification strategy rests on the assumption that the cross-cohort difference in smoking between US white males and females follows a "smooth-enough" trend and that any departure between 1945 and 1950 from that slowly evolving difference will be attributed to the extra education brought about by the draft avoidance behavior. For validation and comparison purposes, we also perform the estimation using different groups. First, we include the veterans to the male and female grouping analysis. Second, we perform the estimation using the non- 
veteran males only. In the latter case, the identification of a treatment effect rests entirely on the assumption that the independent effect of age for males is sufficiently smooth. Finally, given the possibility that males and females may have reacted differently to the release in January of 1964 of the Surgeon General's report on smoking, we perform a falsification analysis. We use data from Canada's 1994 and 1999 National Population Health Surveys (NPHS) to verify whether our results can be replicated in an environment in which they should not be present. The three checks we perform support our initial findings that education plays an important role in convincing people never to smoke, and that it somehow contributes less to smoking cessation. So while our results are also consistent with the unobserved discount rate being changed à la Becker-Mulligan, which subsequently affects people's decision regarding smoking, education does seem to bring some change in the health behavior.

The paper is structured as follows: the first part briefly reviews the literature on schooling and health and with smoking in particular. The second part will describe the data and methodology. Results will then be presented and followed by a discussion.

\section{Previous Literature}

The Surgeon General's Reports on the Health Consequences of Smoking (U.S. Department of Health, Education, and Welfare (1964), U.S. Department of Health and Human Services $1998,2000,2001)$ provide compelling evidence that smoking increases mortality due to heart disease, cancer and chronic obstructive pulmonary diseases. ${ }^{2}$ In concluding their extensive survey, Chaloupka and Warner (2000) point out that "the use of tobacco, and particularly cigarette smoking, constitutes one of the great public health plagues of the latter half of the twentieth century, and one sure to define much of the global health status far into the 21st century as well."

The literature has made progress towards a better understanding of the determinants of smoking behavior, including the recent contributions on "rational addiction" (see Becker and Murphy (1988) for the original theoretical exposition, and Becker et al. 1991 and 1994,

\footnotetext{
${ }^{2}$ Mortality increases with quantity smoked and length of smoking career. It increases with tar and nicotine levels. However, mortality decreases following cessation or reductions in quantity smoked, particularly among healthy quitters. Finally, smoking exhibits similar effects on morbidity (Moore and Hughes (2000)).
} 
Chaloupka and Warner (2000), and Gruber and Koszegi (2001) for evidence supporting the rational addiction model).$^{3}$

While prices and income are obvious determinants of tobacco consumption, their effects appear relatively limited, as most studies report low elasticities (if significant at all, Chaloupka and Warner (2000)). Consequently, many public health analysts suggest that an additional benefit of restricting smoking would be to lower health care costs and have emphasized a combination of factors besides tax increases to favor smoking cessation and a reduction in starting smoking (Moore and Hughes (2000)). ${ }^{4}$

Education appears to exert an important influence on the smoking behavior of individuals. ${ }^{5}$ For instance, numerous studies report that high school dropouts are much less likely to have never smoked, while those who have some schooling beyond high school and/or college are more likely to have never smoked or, if they did smoke at one time, are more likely to have subsequently quit. Two explanations for the relationship between education and smoking have mainly been suggested. ${ }^{6}$ The first is the allocative efficiency that education brings to health, either because education makes people better decision-makers (Grossman (1975)) and/or because more educated people have better information about health (Kenkel (1991), Rosenzweig and Schultz (1991)). The second explanation suggests that the correlation could be caused by a third unobserved variable that affects both education and health, for example genetic characteristics. As such, the measurement of the impact of education on health would suffer from omitted variable bias.

A few studies (Berger and Leigh (1989), Sander (1995), Leigh and Dhir (1997)) have used instrumental variable estimation with measures of health such as smoking or exercise. For instance, Sander finds that schooling has a positive effect on the odds that men and women

\footnotetext{
${ }^{3}$ Gruber and Koszegi modify the basic framework by incorporating time-inconsistent preferences, leading to different normative implications.

${ }^{4}$ See Evans et al. (1999) for evidence that smoking bans have a significant impact on smoking.

${ }^{5}$ Besides the smoking link, a large and positive correlation between education and health in general has been documented for a long time. See Ippolito (2002) for a review of the studies linking the amount of education an individual has attained and her health status. Another type of education often mentioned is the specific public health education programs targeted at smokers (U.S. Department of Health and Human Services (2000)). This paper does not discuss this specific type of programs, though the allocative efficiency argument makes it certainly possible that the targeted programs' efficiency can be enhanced by an individual's higher educational attainment.

${ }^{6}$ There are also other possible explanations. For instance, Perri (1984) and Currie and Hyson (1999) suggest that poor health results in little education.
} 
quit smoking. One potential criticism of these papers involves the choice of instruments. All these studies use parents background/education as instruments, and these are likely to be correlated with children's health, particularly given that health stocks acquired during childhood or gestation have persistent health effects into adulthood. Other studies looking at health outcomes and which make use of instrumental variables to control for the endogeneity of educational attainment include Lleras-Muney (2002) who uses compulsory schooling laws to analyze the effect of schooling on mortality, Adams (2002) and Arendt (2002) who exploit compulsory schooling age differences when individuals were of school age, and Arkes (2001) who uses variation in unemployment rates during periods in which individuals were of school age. In addition, examining the effect of maternal education on health, Currie and Moretti (2002) use data about the availability of colleges in the woman's country in her 17th year as an instrument for education and find that higher education reduces the probability that a new mother will be smoking.

Having exogenous sources of variation in educational attainment would appear to be crucial in studying the correlation between education and smoking. As Fuchs (1982) pointed out, discount rates would also explain the correlation: people who are impatient invest little in education and health, while people who are patient invest a lot in both. ${ }^{7}$ Indeed, in a standard cross-sectional analysis Farrell and Fuchs (1982) find that eventual completed schooling predicts smoking just as well at age 17 as it does at age 24 , suggesting that a college education does not explain less smoking among the better educated.

Blending the allocative efficiency and the time preference ideas, Becker and Mulligan (1997) posit that higher education teaches individuals how to be more patient. Though it may be observationally equivalent to Fuchs (1982)'s hypothesis, their model suggests that one should consider that some of the benefits associated with low discount rate behavior should be counted as a return to schooling.

Regardless of its origin, the nature of the link between education and smoking may have

\footnotetext{
${ }^{7}$ There is no empirical study of education and smoking that explicitly controls for discount rates. Ippolito (2002), however, looks at the link between smoking, education and savings using the Health and Retirement Survey and finds that savings propensity appears to be a key component to health outcome, a result that is more in line with Fuchs (1982) or Becker and Mulligan (1997). Other studies (Munasinghe and Sicherman (2000), Evans and Montgomery (1994)) take as an assumption that those involved in unhealthy activities have a high rate of time preference.
} 
some policy implications for education. For instance, if the effect of schooling on health operates through time preference, the current school-based programs to promote health knowledge may have smaller payoffs than programs that encourage future-oriented behavior in the general population (Grossman (2000)).

\section{Data and Methodology}

\subsection{Data Description and Analysis}

We use the 1995, 1996, 1998, and 1999 Current Population Survey Tobacco Supplements. In addition to the standard items on personal characteristics such as age, gender and education, the supplements contain fairly detailed questions on smoking incidence and intensity at the time of the interview as well as the age at which respondents started smoking "fairly" regularly. The latter question is asked to both self-respondents and proxy respondents. However, only self-respondent former smokers are asked questions about the age at which they stopped smoking regularly or completely, and about the number of cigarettes smoked. ${ }^{8}$

One crucial piece of information contained in the CPS is the Veteran status question. This is important for the simple reason that war veterans are more likely to smoke compared to the rest of the population, as documented in Bedard and Deschênes (2003) in the case of World War II veterans. We find that it also holds for Vietnam War veterans. Consequently, although previous work by e.g. Bound and Turner (1999) and Stanley (2003) has found that the various "G.I. Bills" have had an effect on the educational attainment of War Veterans, the independent effect of education on smoking, assuming there is any, would be potentially dwarfed by the direct effect of war participation unless we can control for it.

The main sample consists of white male and female U.S born citizens aged at least 25 and born after $1934 .^{9}$ Below we will show the results for two sub-samples of males and females: one made of non-veterans only, and the other including veterans. The 1934 cutoff point is

\footnotetext{
${ }^{8}$ Smokers are defined in the CPS as having smoked at least 100 cigarettes in their life.

${ }^{9}$ The lack of information on citizenship/country of birth made the use of the earlier (September 1992, January 1993, and May 1993) Supplements problematic. Given our identification strategy and our desire to control to some extent for "country-specific norms" in terms of smoking, we think our approach applies best in the case of U.S. born citizens.
} 
largely chosen because of concerns that may be raised regarding how representative a sample of non-veterans old enough to have been potentially eligible to participate in either World War II or the Korean War would be. Given the large fraction of males who participated in these two conflicts, especially during the Second World War, those who were exempted from service are likely to exhibit a relatively greater incidence of various health limitations. It can of course be argued that a large fraction of US males participated in the Vietnam War as well. However, draft avoidance through education-related deferments is a phenomenon that was not as important in the other two conflicts; in fact, it was not possible in the case of World War II (Card and Lemieux (2002)). Another reason to focus on individuals born starting in 1935 is that since the tobacco consumption questions are asked in the mid to late 90 's, many people in their sixties and above have already stopped smoking, irrespective of their education level. ${ }^{10}$

Figure 1 and Table 1 serve as our starting point and simply confirm the well-documented cross-sectional relationship between schooling and smoking. Looking at Figure 1, it is quite clear that smoking incidence, however defined, declines sharply starting with high school graduation and continuing through post-secondary schooling. ${ }^{11}$ Completion of high school appears to be a specific event in determining smoking. The upward sloping portion of the schooling-smoking gradient should be taken with a grain of salt: there are few observations at very low levels of schooling. Next, Table 1 displays various degrees of incidence of cigarette smoking by educational attainment for (non veteran) white males and females. Male smokers who did not complete high school have a 46 percent probability of smoking regularly whereas there is less than an 8 percent probability of finding a smoker among white males with a college degree. ${ }^{12}$ However, the table suggests that the distinction across educational attainment does not apply in absolute terms to those who claim to be occasional smokers. Yet, in relative terms, there is some difference across educational attainment: occasional smokers represent

\footnotetext{
${ }^{10}$ One reason to link education and smoking using a sample of non-veterans is that the experiment we want to exploit, which involves inter-cohort comparisons, would seem to us to be more relevant to that population (more on that below). However, the cost of doing so is to potentially introduce some selection bias. Consequently, to check robustness, we will present the results using both samples.

${ }^{11}$ Note that since the CPS no longer contains a direct question on completed years of schooling, we constructed that measure of educational attainment using Park (1996)'s mapping between the educational attainment categories now reported in the CPS and completed years.

${ }^{12}$ The Supplement defines a regular smoker to be someone who reports smoking (or having smoked) every day for at least six months. The others, among those who have smoked at least 100 cigarettes in their life, are defined to be occasional smokers.
} 
over 30 percent of those declaring to be smoking for those with a college degree whereas occasional smokers are only about 10 percent of the smokers with less than a high school degree. The same patterns are present when we look at the difference in the fraction of people reporting themselves to be former smokers across educational attainment categories. This is particularly true in the case of men. Unconditionally, the percentages are fairly similar but conditional on ever having been a smoker, more education increases the likelihood of being a former smoker. ${ }^{13}$

The next two figures illustrate the experiment we want to exploit. Figure 2a shows the fraction of white males and white females with a Bachelor's degree or more across birth cohorts, while Figure $2 \mathrm{~b}$ depicts the fraction of regular or occasional smokers at the time of the interview. As documented in Card and Lemieux (2002), the enrollment rate of college-age men in the United States between 1965 and 1975 rose and then fell noticeably. For males born between 1945 and 1950, one very short-term benefit of getting into college appeared to be a higher likelihood of avoiding the Vietnam draft, given that the Selective Service issued college deferments to enrolled men that delayed their eligibility for conscription. Card and Lemieux use a counterfactual analysis, using women as the control group, to suggest that the Vietnam-era draft led to a rise in male college attendance rates between 1965 and 1970, and a corresponding rise in college completion rates for males of the first baby-boomer cohort. They explain the increase in college attendance was due to draft avoidance instead of an effect of the G.I. Bill because of the timing of the rise as well as the fact that Vietnam-era veterans did not return to complete their college degree in great numbers after their military service. As can be seen from Figure 2a, the increase in the fraction of males with at least a B.A. degree is quite significant. Turning to Figure $2 \mathrm{~b}$, the visual evidence provides support to the notion that relative to women, males born between 1945 and 1950 were less likely to report smoking on a regular basis in the mid to late 90 's.

The relative change in educational attainment between non-veteran males and females of the 1945-50 cohort is not quite so apparent in Figure 3a where we use data from the veteran-

\footnotetext{
${ }^{13}$ Note, though, that we are mixing all the birth cohorts together, which can be misleading given the sharp changes in both educational attainment and smoking across cohorts. The same computations done with the 1945-50 birth cohort only do suggest that, even unconditionally, more educated individuals are more likely to be former smokers, especially in the case of females.
} 
only male subsample along with the full sample of females. This provides visual support to the point made above that the GI Bill did not seem to generate a very large increase in the relative educational attainment of post-war men. Also, we can see in Figure 3b that there is no evidence, at least visually, that smoking incidence decreased for Vietnam veterans born between 1945 and 1950 relative to women: if anything, the reverse is true.

We also exploit the questions on the age at which people started smoking as well as the age when they stopped smoking to compute the number of years during which they smoked regularly. ${ }^{14}$ This might be another outcome that would potentially be affected by education. Figure 4 shows the inter-cohort trends by gender in the number of years during which former smokers smoked regularly. We can see that there is some evidence that, controlling for the downward trend, the male-female differential in years spent smoking decreased for the cohorts born between 1945 and 1950, although it is not as visually obvious as the evidence presented in Figure $2 \mathrm{~b}$ for the fraction of smokers at interview time.

\subsection{Statistical Framework}

We build upon Card and Lemieux (2002)'s results to set up a quasi-experiment in order to probe further the correlation between smoking and education. We use a birth cohort dummy for males born between 1945 and 1950 as an instrument for education. In effect, we posit that the males of the first baby boom cohort were subject to a particular treatment compared to females: getting a college education as a means of avoiding the draft. The maintained assumption is that the cross-cohort difference in smoking between males and females follows a "smooth-enough" trend and that any departure between 1945 and 1950 from that slowly evolving difference will be attributed to the extra education brought about by the draft avoidance behavior. Note that, for comparison purposes, we will also present results using males only. In that case, the identification of a treatment effect rests entirely on the assumption that the independent effect of age for males is sufficiently smooth. ${ }^{15}$

\footnotetext{
${ }^{14}$ The information on the smoking status of former smokers (i.e. regular or occasional) is obtained from self-respondents only. Note that although people are asked about their starting age, the question refers to when they started smoking "fairly regularly". So there is a bit of ambiguity as to whether it really reflects the age at which they started smoking regularly.

${ }^{15}$ The case in which we use only males is similar in spirit to the so-called regression discontinuity design. See Hahn et al. (2002) for a formal discussion on the identification of treatment effects in such models.
} 
The added benefit from using females as our control group, which allows us to avoid using stronger identifying conditions, is that one may be worried about the impact of the release in January of 1964 of the Surgeon General's report on smoking. Looking at Figure 2b it would appear that there is a breaking point (reduction) in the steady rise in the smoking incidence up to those who were born in 1960. Indeed, both white male and female individuals of the first baby boom cohort (born between 1945 and 1950) appear to buck the upward trend in smoking incidence, the break being perhaps more obvious in the case of females. Note that these individuals were between 15 and 20 years old, a crucial period in terms of starting smoking, when the Surgeon General published his first report on the adverse consequences of tobacco on health. ${ }^{16}$ They may have been relatively open to the message, compared to other cohorts. The crucial assumption, then, is that both males and females reacted in a "sufficiently similar" way.

The 1964 report created quite a stir in the media. It was ranked among the top news stories of 1964. It could conceivably have affected this cohort. But, again, what is required in terms of identification is not that no one reacted to the release of the report, just that men born between 1945 and 1950 did not process the information too differently compared with women of the same cohort. Still, it would be useful to have direct evidence that our identifying assumption appears to be reasonable. With that in mind, we pulled data from Canada's 1994 and 1999 National Population Health Surveys (NPHS) to reproduce the equivalent of Figure 2b. ${ }^{17}$ Figure 5 shows the fraction of males and females smoking regularly by birth cohort. ${ }^{18}$

\footnotetext{
${ }^{16}$ Of course, there are various determinants of the decision to start smoking, among them economic (prices, income) social (role models, group pressures) etc.. Most experts agree that the adolescent years represent a crucial period where these factors come into play. See, for instance, the Surgeon General Report 2000, chapter 3 , on the various determinants of taking up smoking.

${ }^{17}$ We selected males and females aged at least 25 who were born starting in 1935 . We excluded respondents from Québec for two reasons. The first one is that the 1999 survey did not ask a question about the mother tongue of the respondent, and French-speaking Quebeckers smoke more than other Canadians. The second, perhaps more important, reason is that Québec implemented a major reform in its educational institutions starting in the mid-60's. Although the cohorts born after 1950 would be more likely to have been impacted by the important expansion in access to post-secondary education, it is possible that males born earlier could have taken advantage of the new educational opportunities. Indeed, we find that of the $12 \%$ of all French-speaking Québec males aged between 20 and 34 at the time of the 1971 Census who attended school, $22 \%$ were aged between 25 and 29 and over $18 \%$ were aged between 30 and 34 . In contrast, of all the $12.8 \%$ of English-speaking males in the same age range living elsewhere in Canada who attended school, $19 \%$ were aged between 25 and 29 and less than $12 \%$ were aged between 30 and 34 . These differences in school enrollment behavior across provinces could have repercussions on the inter-cohort variations in smoking behavior.

${ }^{18}$ One disadvantage of the NPHS is the fact that age is bracketed in 5-year intervals.
} 
Although there is evidence of a trend break between the 45-49 and the 50-54 birth cohorts, there is little suggesting that males and females adjusted their trends differently. ${ }^{19}$

\section{Results}

Table 2 presents the estimates of equations 1 and 2 to explore the effects of education on smoking for our treatment groups of white males of the first baby boomer generation using other white males and females as control groups. ${ }^{20}$ The first panel of the table looks more carefully at the decision to start smoking with a comparison between smokers and those who never smoke whereas the second panel focuses more on the decision to quit smoking using a comparison between current and former smokers, the latter on their own or together with those who never smoked.

Each panel shows the development of the estimation until the second stage. The panel begins with the estimates of the simple, cross-sectional effect of education on smoking using three different measures of educational attainment: years of schooling, at least some college education, and college completion with a B.A. degree or more. The second set of estimates presented in the panel is the effect of the cohort dummy on our variables of interest. Finally, the bottom part reports the IV estimates of the effect of education on smoking, again with the three different measures of education. ${ }^{21}$

The first two columns of Panel A of Table 2 provides the estimates when the comparison is done using those who currently smoke at the time of the interview against those who report

\footnotetext{
${ }^{19}$ The presence of a trend break in the Canadian data, like in the U.S. data, does suggest that a similar factor played a role in both countries, the main suspect being the 1964 Surgeon General's report. Interestingly, Canada began regular monitoring of smoking prevalence rates in 1965, that is, soon after the release of the U.S. Surgeon General's report (Health Canada (2001)).

${ }^{20}$ In Appendix A we report the results using a bivariate probit model. Although the bivariate probit might appear to be more appropriate than a linear model given the discrete nature of the outcomes, we nevertheless prefer our IV results. First, we find the high precision of the estimates somewhat suspect, or at least a direct consequence of using a fully parametric approach. Second, and perhaps more importantly, given the virtual absence of a smoking outcome/instrument relationship when we compare current regular to former regular smokers, we just do not think that the estimates are very credible. Still, at least in the case of the impact of having at least B.A. degree, the magnitude of the coefficients is roughly similar across methods, although this is not true for all specifications.

${ }^{21}$ Each regression contains an overall as well as a male-specific age polynomial (quartic) along with dummies for gender, whether there is another regular smoker in the household, living in a metropolitan area, marital status, region of residence (4 categories), family income (14 income brackets), and labor force status (6 categories).
} 
having never smoked in their life. The comparison between those who report ever smoking in their life (i.e. currently smoking and former smoker) and those who never smoked is shown in columns 3 and 4 of Panel A. For each estimation, we report the results obtained using all respondents (self and proxy) and self-respondents only.

The first thing to note is that education is negatively related to start smoking. Not surprisingly, whether one uses years of schooling, a dummy for college attendance or one for college completion, the estimates shown in the first section of Panel A in the four column are all negative and highly statistically significant. Furthermore, the gradient is stronger when using those who currently smoke only. If we look at the reduced form linking smoking and the birth cohort dummy, we can see that the difference in the incidence of smoking between non veteran males and females born between 1945 and 1950 decreases, controlling for all other observables. ${ }^{22}$ Second, the panel shows that white males of the first baby boomer cohort were more likely to have received additional years of education, to have attended college and have completed college. These results indicate that our excluded instrument does seem to be a good predictor of educational attainment. For example, the F-statistic for the excluded instrument in the case where we use years of education is over 40 . Of course, the validity of our results rests on the assumption that the process which led those males to get more schooling was not also independently making them smoke less. This is one of the main concerns which one could legitimately have regarding our identification strategy. ${ }^{23}$ It is also the main reason why looking at the behavior of the same cohorts of men and women in Canada can be informative.

The full instrumental variable estimation results of the first column show that, however measured, more education leads to a significant reduction in smoking. In fact, it would

\footnotetext{
${ }^{22}$ The reduced form estimates are always lower when using self-respondents only. What we find when we look at potential reasons for the difference is that a) self-respondents are under-represented in the treatment group relative to other males and to females; and, more importantly, b) for some reason self-respondents are more likely to report smoking if they are in the treatment group while they are less likely to report smoking if they are either females or males born in other cohorts. Interestingly, when we use all males, veterans and non veterans alike, the discrepancy in the reduced form estimates between the full sample and the self-respondent sample almost entirely disappears.

${ }^{23}$ We have also used the "induction risk" measure constructed by Card and Lemieux which represents the average number of inductions over the years each cohort was 19 to 22 years of age divided by an estimate of the size of the cohort. Whether we use that measure as an instrument for education for the 1935-1959 cohorts (the ones studied by Card and Lemieux) or the 1935-1974 cohorts we use in our base specifications, the qualitative conclusions are the same as when we use the birth cohort dummy. The main difference is in the precision of the estimates, which is greater when we instrument with the birth cohort dummy.
} 
appear that there is no reason to believe that the cross-sectional relationship estimates shown at the top of Panel A overstate the impact of education. Thus, education appears to have a causal effect on starting smoking when comparing current smokers with those who never took on the habit. The effect of education is somewhat dampened when one excludes the proxy respondents but remains nevertheless significant. When we include the former smokers with those who currently smoke and compare them to those who never smoke, column 3 shows that more education contributes to less smoking, although the effect is reduced compared to column 1 .

This reduction of the causal effect of education is further highlighted by Panel B of Table 2. For instance, the first two columns present the comparison between individuals who are smoking every day at the date of the interview and those who are defined to be former smokers as well as those who never smoke. The probit results of education on smoking show the usual strong negative relationship between education and smoking. However, although the smokingeducation gradient is highly significant, the magnitude of the coefficients is reduced by about $20 \%$ across all educational attainment measures, relative the magnitude of the estimates in columns 1 and 2 of Panel A. This is suggestive that putting former smokers in the same group as those who never smoked may result in grouping together two fairly different types of individuals. The estimates from the instrumental estimation are accordingly quite a bit smaller than those obtained in Panel A and their statistical significance is somewhat marginal in the case of self-respondents.

When, in the last four columns, we remove the "nevers" from the sample, we can see that the evidence that men of the 45-50 birth cohort smoke less becomes even weaker, particularly when we focus on self-respondents. Indeed, when we compare current regular smokers with former regular smokers we basically do not find any evidence of a relative reduction in smoking at the time of the interview. ${ }^{24}$ What we also find of interest is that the first-stage regression is also weaker in terms of the magnitude of the parameter estimates. In other words, the difference between former and current regular smokers in terms of the likelihood of getting more education as a way to avoid the draft is not quite as large as in the case when we

\footnotetext{
${ }^{24}$ Only self-respondent former smokers were asked about their past smoking status.
} 
compare the two "extreme" cases consisting of current regular smokers and those who never smoked. Although this is only suggestive, it would appear to be consistent with the Becker and Mulligan (1997) argument: once one makes the choice of "investing" in an unhealthy habit, one's discount rate increases thus making that person less likely to make other human capital investment. ${ }^{25}$ Given the lack of evidence of a reduced form relationship between the outcome of interest and the instrument, it is not surprising that the IV estimates are suggestive of a fairly limited role for education in the process leading one to stop smoking.

When we do not limit the male sample to non-veterans only, we can see from Table 3 that basically all of the above-mentioned results hold. Indeed, the IV estimates are at times considerably larger than what we obtained using non-veterans males only. Given that the reduced form linking smoking status to the instrument does not show a substantial change relative to the estimates reported in Table 2, these larger treatment effect estimates stem from the smaller first-stage coefficients. ${ }^{26}$ The fact that the first-stage estimates are quite a bit smaller is not all that surprising considering that, as pointed out in Card and Lemieux (2002), the GI Bill just did not have such a large impact on the enrollment decisions of returning Vietnam War Veterans. Because there is little indication that our sample of nonveterans represents a "special" group of individuals that would lead us to falsely attribute the reduction in smoking of the 45-50 birth cohort to education, we view our Table 2 results as preferable on the grounds that they are derived from what appears to be a more reliable first-stage relationship.

Finally, in case one is still suspicious about comparing the smoking behavior of males and females, we performed the same analysis using male non-veterans only. ${ }^{27}$ Again, except for the

\footnotetext{
${ }^{25}$ Again, we do not want to make too strong a claim in that regard. However, when we perform the same estimation as in columns 5 and 6 of Panel B with a subsample consisting of individuals who report having started smoking regularly at or before 17 , we find that the first-stage is much weaker compared to when we estimate it with the subsample made of those reporting having started smoking regularly after 17.

${ }^{26}$ Note, however, that the reduced form estimates obtained with the sample of self-respondents are now much closer to the ones obtained with both proxy- and self-respondents. Thus, if any selection bias is introduced when we focus only on non-veterans, it would appear to go in the direction of understating the inter-cohort changes in smoking status.

${ }^{27}$ This concern about whether it is really appropriate to use women as a control group is not groundless: witness the Surgeon General's 2001 report which focuses specifically on why smoking among females has picked up in recent decades. A look at Figure 2b, however, shows that while it is true that women born in the 55-65 cohorts caught up with men in terms of every day smoking incidence, the later cohorts of men have diverged from their female counterparts. One cautionary remark would be that the size of the mid-70's cohorts is not very large in our sample because of the requirement that individuals be at least 25 years-old.
} 
smaller sample sizes, the same overall conclusions emerge: education does seem to markedly reduce the probability of becoming a smoker while it plays at best a modest role in inducing regular smokers to quit. In the latter case, all the estimates shown in columns 5 and 6 of Tables 1,2 , and 3 would seem to indicate that some important factor other than education makes people quit smoking regularly and that this other factor happens to be correlated with educational attainment.

As pointed out earlier, using men imposes the stronger requirement that smoking follows a smoothly evolving time trend, which allows the more or less sudden departure from the trend estimated for the 45-50 birth cohort to be attributed to the equally sharp departure in educational attainment. Both Figure 3a and Figure 4 with Canadian data would suggest that a trend break occurred starting with the mid-forties cohorts. Consequently, this threatens the identification strategy when using males only, although it would appear that one would have to come up with a reason explaining why the after 1950 cohorts somehow ignored the information contained in the Surgeon's General 1964 report relative to their earlier counterparts. In fact, the Surgeon General reiterated the case against smoking in several post-1964 reports.

Although what we find above suggests that education appears to be not such an important factor in inducing people to quit smoking, it may that there are some people who do respond to the treatment and that a more refined outcome such as years spent smoking regularly would be impacted relative to just using the smoke/not smoke outcome. In Table 5 we report the results showing the impact of education on the length of one's smoking career, but only for those who have stopped already. In some sense, for those people, education cannot explain why they stopped for the simple reason that they are all former smokers. However, it may still be the case that education played a role in the timing of their decision. The results in columns 1 and 3 would suggest that the OLS estimates do seem to reflect a causal mechanism. In fact, the IV estimates are substantially larger than their corresponding OLS coefficients, although they are quite a bit imprecise as well. The evidence is a lot weaker when we include veterans in the sample. In fact, there is hardly any evidence of a reduced form relationship between years of smoking and the instrument. ${ }^{28}$

\footnotetext{
${ }^{28}$ Interestingly, when we include current regular smokers in the sample of non veterans, the years of smoking/education reduced form (estimated with a Tobit) is fairly weak as well, thus qualitatively replicating with
} 


\subsection{Falsification}

Finally, to check whether the results reported above can be replicated in an environment in which one would not expect them to be present, we used the pooled 1994 and 1999 Canadian National Population Health Surveys to perform the same regressions estimated in Tables 1-3. As pointed out earlier, one drawback from using those data sets is that age is reported only in five year brackets. Hence, to construct our age polynomials we used the mid-range age in each birth cohort. ${ }^{29}$

Much like in the case of the US data, the results reported in Table 6 first show a strong negative cross-sectional relationship between smoking and educational attainment. ${ }^{30}$ Next, we can see that there is very little evidence that the difference in smoking incidence between males and females decreased for the 45-50 cohort relative to the other cohorts, although the estimates are not very precise due to the small sample sizes. The first-stage estimates are actually of opposite sign compared to the US results, suggesting that females of that cohort caught up with males. ${ }^{31}$ There is very little in Table 6 which suggests that the male-female difference in smoking for the 45-50 birth cohort occurred due to some other factor that may have coincided with the release of the Surgeon's General report (or any other event) that would likely have had an impact in Canada as well. ${ }^{32}$

\section{Discussion}

Our results support the hypothesis that education allows an individual to select a healthier lifestyle in at least one respect: a higher educational attainment reduces the probability of

a censored outcome what we find when we look at the cruder binary outcome (current regular smoking vs former regular smoking).

${ }^{29}$ The need to have the same birth cohort intervals in both surveys precluded the use of the 1996 NPHS. Note that we get very similar results when we re-estimate the models with the CPS data using the same age intervals as in the Canadian NPHS.

${ }^{30}$ The 1999 survey contains very limited information on educational attainment with only four categories (less than high school, high school completed, some post-secondary, post-secondary with a diploma). So even though the 1994 categories are much more refined, we have to use the lowest common denominator.

${ }^{31}$ When we estimate the same regressions using only Québec, we find that male smoking decreased relative to female at the same time that educational attainment increased. Although the estimates are extremely imprecise, the magnitude of the coefficients is actually very comparable to what we estimate with U.S. data.

${ }^{32}$ The report was front page news in the Toronto Daily Star (now the Toronto Star) (Toronto Daily Star (1964)), Canada's newspaper with the widest circulation, the same day it was released. There were other report-related features in subsequent days. 
taking up smoking. Indeed, if our experiment's hypothesis is valid, those individuals who did not smoke were even less likely to have started smoking as a result of the unexpected increase in education they acquired partly as a draft avoidance strategy.

However, the effect of higher educational attainment on smoking is not symmetrical. We find that the effect of education on quitting smoking appears to be modest. This last result, though, is not very precise and it could still be that a more powerful instrument could identify an effect. Still, the virtual absence of any relative decrease in the fraction of males born between 1945 and 1950 and who smoke regularly suggests to us that, at the very least, the main impact of education on smoking incidence operates through its dissuasive effect on nonsmokers. Another possibility is that the result is valid given the particular nature of tobacco. Nicotine addiction makes it very hard to quit smoking, as many people who quite smoking eventually relapse and may require repeated attempts before they can definitely achieve longterm abstinence. ${ }^{33}$ If one views tobacco dependence as a chronic disease with remission and relapse, it is not clear that a higher educational attainment will cause an individual to wean herself more of the nicotine addiction than other factors such as counseling or pharmacological treatments could. In economic terms a la Becker-Mulligan, it could be that once an individual becomes addicted, she tends to discount the future more heavily than before, leading to an increase in consumption of the harmful substance. Hence, whereas a higher educational attainment might have helped reduce the discount factor of an individual, the nicotine addiction's effect on the discount factor neutralizes the effect of education on her choice of a healthy lifestyle.

This being said, while we cannot reject the hypothesis that education plays no role in influencing the decision to quit smoking regularly, we also find that once we condition on being a former smoker more education reduces the number of years smoking. Thus, while in some sense education cannot explain why they quit smoking, it appears to have a strong impact on how long it takes before deciding to quit, for people belonging in the subsample of those who have stopped.

Another interesting finding is the magnitude of the education effect on taking up smoking.

\footnotetext{
${ }^{33}$ See U.S. Department of Health and Human Services (2000), chapter 4, for a review of the various interventions to promote smoking cessation.
} 
In tables 2-4, the IV estimate is consistently higher than the one found in the cross-sectional regressions. For instance, the estimates in column 1 of table 2 suggest a larger than $100 \%$ increase in the effect of education on taking up smoking for a typical white male. One partial explanation could be due to the attenuation bias caused by measurement error in education. However, the magnitude of the discrepancy makes it doubtful that it can be explained by measurement error alone. Another possibility is that the magnitude of the effect correctly reflects the impact of education on smoking for the individuals who were induced to stay in school so as to avoid being drafted. It is plausible that these individuals had a relatively high discount rate. Consequently, higher educational attainment could have had a larger marginal impact on them in terms of choosing a healthier lifestyle by preventing them to start smoking, possibly through a reduction of the discount factor (Becker and Mulligan (1997)). Thus, the effect found in this paper could reflect how these high discount rate individuals responded to the treatment consisting of getting post-secondary education. In essence, our results should probably be interpreted in a "local average treatment effect" context (Imbens and Angrist (1994)).

Assuming that the effect of schooling on health mainly operates through time preferences, what we find strongly suggest that, if properly targeted, general interventions that encourage future-oriented behavior may have larger rates of return in the long-run than specific interventions designed, for example, to discourage unhealthy habits such as cigarette smoking, alcohol abuse, or the use of illegal drugs. Future research will be needed to see if individuals treated to more education are also more likely to choose other future-oriented options such as other healthier lifestyle choices, increased savings, or even their children's schooling. 


\section{References}

Adams, Scott, "Educational Attainment and Health: Evidence from a Sample of Older Adults," Education Economics, 2002, 20, 97-109.

Arendt, Jacob, "Does Education Cause Better Health? A Panel Data Analysis Using School Reforms for Identification," 2002. mimeo, Institute of Local Government Studies, Copenhagen.

Arkes, Jeremy, "Does Schooling Improve Adult Health?," 2001. mimeo, Rand Corporation, Santa Monica.

Becker, Gary S. and Casey B. Mulligan, "The Endogenous Determination of Time Preference," Quarterly Journal of Economics, 1997, 112, 729-758.

_ and Kevin M. Murphy, "A Theory of Rational Addiction," Journal of Political Economy, $1988,96,675-700$.

_, Michael Grossman, and Kevin M. Murphy, "Rational Addiction and the Effect of Price on Consumption," American Economic Review, 1991, 81, 237-241.

_ , _, and _ ,"An Empirical Analysis of Cigarette Addiction," American Economic Review, $1994,84,396-418$.

Bedard, Kelly and Olivier Deschênes, "The Long Term Impact of Military Service on Health: Evidence from World War II Veterans," 2003. Working Paper, Department of Economics University of California, Santa Barbara.

Berger, Mark C. and J. Paul Leigh, "Schooling, Self-Selection, and Health," Journal of Human Resources, 1989, 24, 433-455.

Bound, John and Sarah Turner, "Going to War and Going to College: Did World War II and the G.I. Bill Increase Educational Attainment for Returning Veterans?," 1999. National Bureau of Economic Research Technical Working Paper No. w7452, Cambridge MA, Forthcoming in the Journal of Labor Economics. 
Card, David and Thomas Lemieux, "Did Draft Avoidance Raise College Attendance During the Vietnam War?," February 2002. Working Paper no. 46, University of California, Berkeley, Center for Labor Economics.

Chaloupka, F.J., "Rational Addictive Behavior and Cigarette Smoking," Journal of Political Economy, 1991, 99, 722-742.

Chaloupka, F.J and K.E. Warner, "The Economics of Smoking," in J. P. Newhouse and A. Cuyler, eds., Handbook of Health Economics, Vol. 1B, North Holland, 2000, pp. 15391612 .

Currie, Janet and Enrico Moretti, "Mother's Education and the Intergenerational Transmission of HUman Capital: Evidence from College Openings and Longitudinal Data," 2002. National Bureau of Economic Research Technical Working Paper No. w9360, Cambridge MA.

_ and Rosemary Hyson, "Is the Impact of Health Shocks Cushioned by Socio-Economic Status? The Case of Low Birth Weight," American Economic Review, Papers and Proceedings, 1999, 89, 245-250.

Evans, William N. and Edward Montgomery, "Education and Health: Where There's Smoke There's an Instrument," 1994. National Bureau of Economic Research Technical Working Paper No. w4949, Cambridge MA.

_, Matthew C. Farrelly, and Edward Montgomery, "Do Workplace Smoking Bans Reduce Smoking?," American Economic Review, 1999, 89, 728-747.

Farrell, P. and Victor R. Fuchs, "Schooling and Health: The Cigarette Connection," Journal of Health Economics, 1982, 1, 217-230.

Fuchs, Victor R., "Time Preference and Health: An Exploratory Study," in Victor R. Fuchs, ed., Victor R. Fuchs, ed., University of Chicago Press for the NBER, 1982, pp. 93-120.

Grossman, Michael, "On the Concept of Health Capital and the Demand for Health," Journal of Political Economy, 1972, 80, 223-255. 
_, "The Correlation Between Health and Smoking," in N.E. Terleckyj, ed., Household Production and Consumption, Columbia University Press for the NBER, 1975, pp. 147-211.

_ , "The Human Capital Model of the Demand for Health," in J. P. Newhouse and A. Cuyler, eds., Handbook of Health Economics, Vol. 1A, North Holland, 2000, chapter 7.

- and R. Kaestner, "Effects of Education on Health," in J.R. Behrman and N. Stacey, eds., The Social Benefits of Education, University of Michigan Press, Ann Arbor, 1997, pp. $69-123$.

Gruber, Jonathan and Botond Koszegi, "Is Addiction "Rational"? Theory and Evidence," Quarterly Journal of Economics, 2001, 116, 1261-1304.

Hahn, Jinyong, Petra Todd, and Wilbert Van der Klaauw, "Identification and Estimation of Treatment Effects with a Regression-Discontinuity Design," Econometrica, 2002, $69(1), 201-209$.

Health Canada, "The National Strategy: Moving Forward. The 2001 Federal Provincial Territorial Progress Report on Tobacco Control," 2001. Prepared by the Advisory Committee on Population Health Working Group on Tobacco Control. Minister of Public Works and Government Services Canada, Ottawa.

Imbens, Guido W. and Joshua D. Angrist, "Identification and Estimation of Local Average Treatment Effects," Econometrica, March 1994, 62 (2), 467-475.

Ippolito, R.A., "A Study of Health Human Capital," 2002. mimeo, George Mason University School of Law.

Kenkel, D.S., "Health Behavior, Health Knowledge, and Schooling," Journal of Political Economy, 1991, 99, 287-305.

Leigh, J.P. and R. Dhir, "Schooling and Frailty Among Seniors," Economics of Education Review, 1997, 16, 45-57. 
Lleras-Muney, Adriana, "The Relationship Between Education and Adult Mortality in the United States," 2002. National Bureau of Economic Research Technical Working Paper No. w8986, Cambridge MA.

Moore, M.J. and J.W. Hughes, "The Health Care Consequences of Smoking and Its Regulation," 2000. National Bureau of Economic Research Technical Working Paper No. w7979, Cambridge MA.

Munasinghe, Lalith and Nachum Sicherman, "Why Do Dancers Smoke?," 2000. National Bureau of Economic Research Technical Working Paper No. w8986, Cambridge MA.

Park, Jin Heum, "Measuring education over time: A comparison of old and new measures of eduction from the Current Population Survey," Economics Letters, March 1996, 50 (3), $425-428$.

Perri, Timothy J., "Health Status and Schooling Decisions of Young Men," Economics of Education Review, 1984, 3, 207-213.

Rosenzweig, Mark R. and T.P. Schultz, "Who Receives Medical Care? Income, Implicit Prices, and the Distribution of Medical Services Among Pregnant Women in the United States," Journal of Human Resources, 1991, 26, 473-508.

Sander, W., "Schooling and Quitting Smoking," Review of Economics and Statistics, 1995, $77,191-199$.

Stanley, Marcus, "College Education and the Midcenturies GI Bills," Quarterly Journal of Economics, 2003, 118, 671-708.

Toronto Daily Star, "Cigarets Are a Major Cause of Lung Cancer: U.S. Report," 1964. January 11 , page 1 .

U.S. Department of Health and Human Services, "Tobacco Use Among U.S. Racial/Ethnic Minority Groups: African Americans, American Indians and Alaska Natives, Asian Americans and Pacific Islanders, and Hispanics. A Report of the Surgeon General," 
1998. Department of Health and Human Services, Centers for Disease Control and Prevention, National Center for Chronic Disease Prevention and Health Promotion, Office on Smoking and Health, Atlanta, Georgia.

_ , "Reducing Tobacco Use: A Report of the Surgeon General," 2000. Department of Health and Human Services, Centers for Disease Control and Prevention, National Center for Chronic Disease Prevention and Health Promotion, Office on Smoking and Health, Atlanta, Georgia.

_ , "Women and Smoking: A Report of the Surgeon General," 2001. Department of Health and Human Services, Centers for Disease Control and Prevention, National Center for Chronic Disease Prevention and Health Promotion, Office on Smoking and Health, Atlanta, Georgia. _, "Cigarette Smoking Among Adults in the Unites States, 2000. Morbidity and Mortality Weekly Reports (MMWR)," 2002. Department of Health and Human Services, Centers for Disease Control and Prevention, Atlanta, Georgia. Vol. 51(29), 642-645.

U.S. Department of Health, Education, and Welfare, "Smoking and Health: Report of the Advisory Committee to the Surgeon General of the Public Health Service," 1964. Department of Health, Education, and Welfare, Public Health Service, 1964. PHS Publication No. 1103, Washington, DC. 
Table 1. Incidence of Cigarette Smoking by Educational Attainment.

Never Every Day Some Days Former Smoker

$\begin{array}{rllll}\text { White Males (N=82,079) } & & & & \\ \text { Less Than H.S. Degree } & 0.272 & 0.460 & 0.049 & 0.219 \\ \text { High School Degree } & 0.419 & 0.314 & 0.045 & 0.222 \\ \text { Some College } & 0.507 & 0.216 & 0.046 & 0.232 \\ \text { B.A.+ } & 0.686 & 0.077 & 0.035 & \\ \text { White Females (N=115,597) } & & & & 0.165 \\ \text { Less Than H.S. Degree } & 0.383 & 0.409 & 0.042 & 0.202 \\ \text { High School Degree } & 0.483 & 0.273 & 0.041 & 0.220 \\ \text { Some College } & 0.538 & 0.198 & 0.043 & 0.204 \\ \text { B.A.+ } & 0.689 & 0.074 & 0.032 & \end{array}$

Notes. Source: Sept. '95, '98, Jan. '96, '99, May '96, ' 99 CPS Tobacco Supplements. Only Non Veterans are included. 
Table 2. Instrumental Variable Estimates of the Effect of Education on Smoking.

Panel A.

(1)

Smoking Regularly vs. Never Smoked

Dep. Variable:

Smoking Every Day at Interview $=1$

$\begin{array}{lc}\text { Self \& Proxy } & \text { Self-Respondents } \\ \text { Respondents } & \text { Only }\end{array}$

$$
\text { Only }
$$

(3)

(4)

Smoking Every Day or Some Days at Interview or Being a Former Smoker=1

Self \& Proxy Self-Respondents

Smoking-Education Probits

Yrs. of Schooling
Some or Completed College
B.A. Degree or More

Reduced Form Smoking (Probit)

$\begin{array}{ll}-0.0386 & -0.0443 \\ (0.0007) & (0.0008) \\ -0.1564 & -0.1653 \\ (0.0030) & (0.0034) \\ -0.2026 & -0.2085 \\ (0.0027) & (0.0031) \\ & \\ -0.0313 & -0.0237 \\ (0.0081) & (0.0097)\end{array}$

$\begin{array}{ll}-0.0324 & -0.0367 \\ (0.0006) & (0.0007) \\ -0.1232 & -0.1314 \\ (0.0028) & (0.0032) \\ -0.1780 & -0.1847 \\ (0.0030) & (0.0033) \\ -0.0269 & -0.0198 \\ (0.0077) & (0.0090)\end{array}$

Reduced Form Education

$$
\begin{aligned}
& \text { Yrs. of Schooling (Linear reg.) } \\
& \text { Some or Compl. Coll. (Probit) } \\
& \text { B.A.+ (Probit) }
\end{aligned}
$$

Instrumental Variable Estimates
Yrs. of Schooling

Some or Compl. Coll.

B.A.+

N

$\begin{array}{cc}0.3246 & 0.3846 \\ (0.0491) & (0.0574) \\ 0.0612 & 0.0556 \\ (0.0093) & (0.0110) \\ 0.0665 & 0.0724 \\ (0.0094) & (0.0112)\end{array}$

(0.0094)

(0.0112)

$\begin{array}{ll}-0.0841 & -0.0528 \\ (0.0237) & (0.0223) \\ & \\ -0.5617 & -0.4678 \\ (0.1625) & (0.2072) \\ & \\ -0.4448 & -0.3046 \\ (0.1215) & (0.1283)\end{array}$

$(0.0090)$ 
Panel B.

(1)

(2)

(3)

(4)

(5)

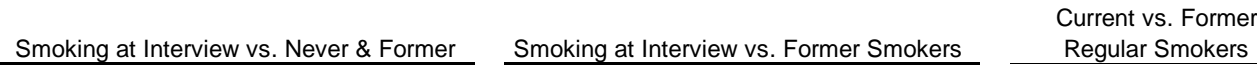

\section{Dep. Variable:}

\section{Smoking Every Day or Some Days at} Interview $=1$

$$
\begin{array}{cc}
\text { Self \& Proxy } & \text { Self-Respondents } \\
\text { Respondents } & \text { Only }
\end{array}
$$

Smoking Every Day at Interview==1

Self \& Proxy
Respondents

Only

Smoking Every Day or Some Days at Interview=

Self-Respondents

Only

$-0.0365$

(0.0012)

$-0.1326$

$(0.0049)$

$-0.1733$

$(0.0063)$

$-0.0033$

$(0.0131)$

$-0.0085$

$-0.0203$

-0.0132
$(0.0076)$

$-0.0178$

Reduced Form Education

Yrs. of Schooling (Linear reg.)

Some or Compl. Coll. (Probit)

B.A.+ (Probit)

Instrumental Variable Estimates

Yrs. of Schooling

Some or Compl. Coll.

B.A.

$\begin{array}{cc}0.3075 & 0.3504 \\ (0.0387) & (0.0447) \\ 0.0621 & 0.0634 \\ (0.0074) & (0.0086) \\ 0.0668 & 0.0706 \\ (0.0074) & (0.0087) \\ & \\ -0.0455 & -0.0291 \\ (0.0181) & (0.0183) \\ -0.2772 & -0.1988 \\ (0.1107) & (0.1262) \\ & \\ -0.2237 & -0.1549 \\ (0.0879) & (0.0976) \\ & \\ 107,670 & 163910\end{array}$

0.2013
$(0.0509)$
0.0503
$(0.0106)$
0.0462
$(0.0082)$


-0.0650
$(0.0437)$
-0.3075
$(0.2054)$
-0.2441
$(0.1594)$
84,130

0.2370
$(0.0582)$
0.0529
$(0.0122)$
0.0497
$(0.0096)$


-0.0299
$(0.0415)$
-0.1601
$(0.2332)$
-0.1259
$(0.1748)$

71,073

0.2508

$(0.0599)$

0.0542

$0.0125)$
0.0478

(0.0095)

$-0.0128$

$(0.0409)$

$-0.0707$

$(0.2256)$

$-0.0569$

(0.1818)

Regular Smokers

moking Every Day

at Interview=1

Self-Respondents

Only

$-0.0366$

$(0.0013)$

$-0.1337$

$(0.0051)$
-0.1770

(0.0066)

$-0.0033$

$(0.0133)$

0.2392

(0.0609)

0.0538

$(0.0128)$

0.0463

$-0.0155$

(0.0438)

$-0.0814$

$(0.2312$

$-0.0666$

(0.1886)

68,794

64,811

Note. Male sample includes non Veterans only. Robust standard errors in parentheses. The instrument consists of a dummy variable from being a male born between 1945 and 1950 Covariates include an overall as well as a male-specific quartic in age polynomial, and dummies for gender, marital status, region of residence, living in a metropolitan area, labor force status (dummy for each category), and family income. 
Table 3. Instrumental Variable Estimates Using Veteran and Non-Veteran Males vs Females.

Panel A.

(3)

Ever Smoked

Smoking Every Day or Some Days at

Interview or Being a Former Smoker=1

$\stackrel{(2)}{(1)}$

Smoking Every Day at Interview $=1$

Dep. Variable:

\section{Smoking-Education Probits}

\section{Yrs. of Schooling}

Some or Completed College

B.A. Degree or More

Vietnam War Participation

And Smoking Status*

Reduced Form Smoking (Probit)

Reduced Form Education

Yrs. of Schooling (Linear reg.)

Some or Compl. Coll. (Probit)

B.A.+ (Probit)

Instrumental Variable Estimates

Yrs. of Schooling

Some or Compl. Coll.

B.A.+

$\mathrm{N}$
Smoking Every Day

Self \& Proxy
Respondents

Self-Respondents
Only $\begin{array}{cc}\text { Self \& Proxy } & \text { Self-Respondents } \\ \text { Respondents } & \text { Only }\end{array}$

Only

\begin{tabular}{cccc}
-0.0448 & -0.0500 & -0.0357 & -0.0392 \\
$(0.0007)$ & $(0.0008)$ & $(0.0006)$ & $(0.0007)$ \\
-0.1753 & -0.1816 & -0.1327 & -0.1374 \\
$(0.0028)$ & $(0.0032)$ & $(0.0026)$ & $(0.0032)$ \\
-0.2252 & -0.2299 & -0.1903 & -0.1952 \\
$(0.0026)$ & $(0.0029)$ & $(0.0028)$ & $(0.0031)$ \\
& & & \\
0.1495 & 0.1560 & 0.1282 & 0.1300 \\
$(0.0072)$ & $(0.0084)$ & $(0.0056)$ & $(0.0064)$ \\
-0.0295 & -0.0270 & -0.0248 & -0.0245 \\
$(0.0064)$ & $(0.0076)$ & $(0.0060)$ & $(0.0070)$ \\
& & & \\
& & & \\
0.2217 & 0.2638 & 0.1860 & 0.2205 \\
$(0.0358)$ & $(0.0417)$ & $(0.0278)$ & $(0.0320)$ \\
0.0507 & 0.0482 & 0.0435 & 0.0458 \\
$(0.0074)$ & $(0.0086)$ & $(0.0059)$ & $(0.0067)$ \\
0.0540 & 0.0591 & 0.0453 & 0.0505 \\
$(0.0072)$ & $(0.0086)$ & $(0.0056)$ & $(0.0066)$ \\
& & & \\
-0.1299 & -0.1000 & -0.1159 & -0.0941 \\
$(0.0321)$ & $(0.0296)$ & $(0.0318)$ & $(0.0297)$ \\
& & & \\
-0.6760 & -0.6591 & -0.5891 & -0.5410 \\
$(0.1680)$ & $(0.2080)$ & $(0.1632)$ & $(0.1770)$ \\
-0.5870 & -0.4947 & -0.5155 & -0.4486 \\
$(0.1369)$ & $(0.1440)$ & $(0.1357)$ & $(0.1394)$ \\
& & & \\
165,925 & 135,073 & 227,027 & 186,833 \\
& & & \\
\hline
\end{tabular}

Note. All males are included. Robust standard errors in parentheses. The instrument consists of a dummy variable for

being a male born between 1945 and 1950. Covariates include an overall as well as a male-specific quartic in age polynomial,

and dummies for gender, marital status, region of residence, living in a metropolitan area, labor force status (dummy for each

category), and family income. *Estimate is obtained controlling for years of education in addition to the other regressors. 
Panel B.

(1)

Smoking at Interview vs. Never \& Former

Dep. Variable: Smoking Every Day or Some Days at Interview $=1$

$\begin{array}{cc}\text { Self \& Proxy } & \text { Self-Respondents } \\ \text { Respondents } & \text { Only }\end{array}$

Smoking-Education Probits

Yrs. of Schooling

Some or Completed College

B.A. Degree or More

Vietnam War Participation

And Smoking Status*

Reduced Form Smoking (Probit)

Reduced Form Education

Yrs. of Schooling (Linear reg.)

Some or Compl. Coll. (Probit)

B.A.+ (Probit)

\section{Instrumental Variable Estimates}

Yrs. of Schooling

Some or Compl. Coll.

$$
\text { Only }
$$

-0.0357
$(0.0006)$
-0.1320
$(0.0026)$
-0.1630
$(0.0024)$

0.0883
$(0.0059)$

-0.0107
$(0.0058)$

$(0.0067)$

0.0505
$(0.0066)$

0.0453

(0.0056)

$-0.0647$

-0.0647
$(0.0265)$

$-0.0443$

$(0.0254)$
(3)

Smoking at Interview vs. Former Smokers Smoking Every Day at Interview==1 Self \& Proxy

Self-Responden

-0.0417
$(0.0010)$
-0.1480
$(0.0039)$
-0.1996
$(0.0048)$
0.0546
$(0.0074)$

-0.0112
$(0.0081)$

$-0.0410$

$-0.3287$

-0.2547
$(0.1475)$

$-0.2877$

-0.2111
$(0.1211)$

$(0.1163)$

186,833
0.0959
$(0.0347)$
0.0347

$(0.0080)$

0.0262

$-0.1045$

-0.1045
$(0.0783)$

$-0.3328$

$(0.2395)$

$-0.3445$

$(0.2455)$

102,255

$$
\text { Only }
$$

$(0.0011)$

$-0.1430$

$(0.0043)$

$-0.1929$

0.0591

(0.0084)

$-0.0057$

$(0.0093)$

0.1337
$(0.0395)$
0.0392

$(0.0395)$
0.0392

0.0392
$(0.0092)$

$(0.0092)$
0.0325

0.0325
$(0.0070)$

Current vs. Former

Regular Smokers

Smoking Every Day or ays at Interview=1

Self-Respondents

Only

$-0.0378$

$(0.0011)$
-0.1329

-0.1329
$(0.0043)$

$-0.1751$

$(0.0055)$

0.0502

$(0.0084)$

$(0.0094)$

.0094)

0.1298
$(0.0402)$
0.0379

$(0.0402)$
0.0379

0.0379
$(0.0093)$

0.0288

0.0288

$-0.0353$

$(0.0661)$

$-0.1406$

$-0.1346$

85,669

$-0.0230$

-0.0230
$(0.0637)$

-0.0914
$(0.2540)$

$-0.0904$

(0.2515)

83,014

(6)

Current Regular. vs. Former Regular Smokers

Smoking Every Day

Self-Respondents

Only

$-0.0379$

$(0.0011)$
-0.1334

$-0.1334$

$(0.0045)$

$-0.1776$

(0.0058)

(0.0085)

-0.0025
$(0.0096)$

0.1198

(0.0409)

0.0386
$(0.0095)$

$(0.0095)$
0.0271

0.0271
$(0.0070)$

$-0.0195$

$(0.0706)$

$-0.0697$

$(0.2534)$

$-0.0742$

78,425

Note. All males are included. Robust standard errors in parentheses. The instrument consists of a dummy variable from being a male born between 1945 and 1950

Covariates include an overall as well as a male-specific quartic in age polynomial, and dummies for gender, marital status, region of residence, living in a metropolitan area,

labor force status (dummy for each category), and family income. *Estimate is obtained controlling for years of education in addition to the other regressors. 
Table 4. Instrumental Variable Estimates Using Non-Veteran Males Only.

Panel A.

(1)

Smoking Regularly vs. Never Smoked

Dep. Variable:

Smoking Every Day at Interview=1

Self \& Proxy

Respondents

Self-Respor

$$
\text { Only }
$$

(3)

Ever Smoked vs. Never Smoked

Smoking Every Day or Some Days at Interview or Being a Former Smoker=
Respondents
Self-Respondents
Only

Smoking-Education Probits

\section{Yrs. of Schooling \\ Some or Completed College}

B.A. Degree or More

Reduced Form Smoking (Probit)

Reduced Form Education

Yrs. of Schooling (Linear reg.)
Some or Compl. Coll. (Probit)
B.A.+ (Probit)

Instrumental Variable Estimates
$-0.0423$

$(0.0011)$

$-0.1848$

$(0.0050)$

$-0.2254$

(0.0044)

$-0.0311$

$(0.0087)$

$(0.0488)$

0.0595

0.0094

0.0683

$(0.0099)$

$-0.0821$

(0.0247)

$-0.5467$

$(0.1685)$

$-0.4298$

$(0.1253)$

60,609
$-0.0480$

$(0.0013)$

$-0.1949$

$(0.0059)$

$-0.2276$

(0.0052)

$-0.0230$

(0.0103)

$\begin{array}{ll}-0.0371 & -0.0417 \\ (0.0010) & (0.0011) \\ -0.1546 & -0.1655 \\ (0.0045) & (0.0052) \\ -0.2040 & -0.2092 \\ (0.0046) & (0.0053) \\ & \\ -0.0256 & -0.0183 \\ (0.0079) & (0.0092)\end{array}$

0.3680

(0.0570)

0.0527

(0.0109)

0.0745

(0.0118)

$-0.0506$

(0.0233)

$-0.4533$

$(0.2183)$

$-0.2906$

(0.1335)

44,557
0.2949

$(0.0385)$

0.0615

$(0.0075)$

0.0689

(0.0077)

$-0.0778$

(0.0247)

$-0.4669$

(0.1502)

$-0.3764$

(0.1172)

82,079

0.3367

(0.0445)

0.0618

$(0.0086)$

0.0733

$(0.0091)$

$-0.0478$

(0.0244)

$-0.3240$

(0.1680)

$-0.2515$

(0.1279)

61,537

Note. Sample includes non Veterans only. Robust standard errors in parentheses. The instrument consists of a dummy variable for being a male born between 1945 and 1950. Covariates include a quartic in age polynomial, and dummies for marital status, region of residence, living in a metropolitan area, labor force status (dummy for each category), and family income. 


\section{Panel B.}

\section{Dep. Variable:}

Smoking at Interview vs. Never \& Former

Smoking Every Day or Some Days at Interview=1

$\begin{array}{lc}\text { Self \& Proxy } & \text { Self-Respondents } \\ \text { Respondents } & \text { Only }\end{array}$

Smoking-Education Probits

Yrs. of Schooling

Some or Completed College

B.A. Degree or More

Reduced Form Smoking (Probit)

Reduced Form Education

Yrs. of Schooling (Linear reg.)

Some or Compl. Coll. (Probit)

B.A.+ (Probit)

Instrumental Variable Estimates

Yrs. of Schooling

Some or Compl. Coll.

B.A.

$\mathrm{N}$
Only

-0.0327
$(0.0010)$
-0.1334
$(0.0043)$
-0.1556
$(0.0042)$
-0.0123
$(0.0079)$

(3)

(4)

Smoking at Interview vs. Former Smokers Smoking Every Day at Interview==1

Self \& Proxy

Self-Respondents

Only

Respondents

$-0.0356$

$(0.0018)$

$-0.1315$

$-0.1785$

$-0.1785$

$-0.0064$

$-0.0064$

$-0.0142$

$(0.0115)$

0.1896

$(0.0506)$

0.0497

$(0.0108)$

0.0466
$(0.0084)$

0.0618

0.0086

0.0615
$(0.0075)$

0.0689

$(0.0091)$

$-0.0636$

(0.0461)

$-0.2932$

(0.2111)

$-0.2309$

(0.1629)

36,247 nt vs. Former

Regular Smokers

Smoking Every Day or

Some Days at Interview=1

Self-Respondents

Only

Only

$\begin{array}{ll}-0.0314 & -0.0311 \\ (0.0019) & (0.0019) \\ -0.1181 & -0.1172 \\ (0.0082) & (0.0084) \\ -0.1520 & -0.1503 \\ (0.0101) & (0.0106) \\ -0.0019 & -0.0018 \\ (0.0133) & (0.0135)\end{array}$

$-0.0019$

$(0.0135)$

at Interview=1

Only

$(0.0084)$

(0.0106)
0.2370

$0.0595)$
0.0529

0.0529

$(0.0126)$

0.0489
$(0.0098)$

$-0.0107$

(0.0432)

$-0.0582$

$(0.2358$

$-0.0462$

$(0.1869)$

26,500
Current Regular. vs. Former Regular Smokers

Smoking Every Day

Self-Respondents

0.225

(0.0606)

0.0524

$(0.0129)$

0.0472

$0.0099)$

$-0.0135$

(0.0465)

$-0.0702$

(0.2419)

$-0.0563$

(0.1941)

25,025

Note. Sample includes non Veterans only. Robust standard errors in parentheses. The instrument consists of a dummy variable from being a male born between 1945 and 1950

Covariates include a quartic in age polynomial, and dummies for marital status, region of residence, living in a metropolitan area, labor force status (dummy for each category), and family income. 
Table 5. The Effect of Education on Years of Smoking Among Former Regular Smokers.

(Dep; Variable: Number of Years Between the Starting Age and the Age at Which One Stops Completely)

\begin{tabular}{|c|c|c|}
\hline $\begin{array}{c}(1) \\
\text { Non Veteran } \\
\text { Males and Females }\end{array}$ & $\begin{array}{l}(2) \\
\text { All Males and } \\
\text { Females } \\
\end{array}$ & $\begin{array}{l}(3) \\
\text { Non Veteran } \\
\text { Males Only }\end{array}$ \\
\hline
\end{tabular}

Dep. Variable:

Number of Years Spent Smoking Regularly

OLS Estimates

Yrs. of Schooling
Some or Completed College

B.A. Degree or More

Reduced Form Years of Smoking

Reduced Form Education

Yrs. of Schooling (Linear reg.)
Some or Compl. Coll. (Probit)
B.A.+ (Probit)

Instrumental Variable Estimates

\author{
Yrs. of Schooling \\ Some or Compl. Coll.
}

B.A.+

$\begin{array}{lll}-0.5280 & -0.5395 & -0.5270 \\ (0.0273) & (0.0258) & (0.0416) \\ -1.7888 & -1.6783 & -1.7585 \\ (0.1215) & (0.1140) & (0.1946) \\ -2.1966 & -2.2673 & -2.1914 \\ (0.1330) & (0.1262) & (0.2116) \\ & & \\ -0.6906 & -0.1264 & -0.6785 \\ (0.3154) & (0.2369) & (0.3154)\end{array}$

$\begin{array}{ccc}0.2874 & 0.1107 & 0.2651 \\ (0.0810) & (0.0566) & (0.0807) \\ 0.0773 & 0.0425 & 0.0764 \\ (0.0159) & (0.0125) & (0.0164) \\ 0.0629 & 0.0234 & 0.0623 \\ (0.0156) & (0.0114) & (0.0158) \\ & & \\ -2.4030 & -1.1415 & -2.5599 \\ (1.2035) & (2.1436) & (1.3274) \\ & & \\ -10.5350 & -3.5003 & -10.7408 \\ (5.1241) & (6.5996) & (5.3448) \\ -11.1510 & & \\ (5.4719) & -5.3941 & -11.3717 \\ & (10.1654) & (5.7121)\end{array}$

29,805

37,003

11,596

Note. Robust standard errors in parentheses. The instrument consists of a dummy variable for being a male born between 1945 and 1950. Covariates include an overall as well as a male-specific quartic in age polynomial, and dummies for gender, marital status, region of residence, living in a metropolitan area, labor force status (dummy for each category), and family income. 
Table 6. Falsification Regressions Using Canadian Data.

(Pooled 1994 and 1999 National Population Health Surveys)

(1)

(2)

(3)

Smoking Reg. vs. Never Smoked Ever Smoked vs. Never Smoked Smoking at Interv. vs. Never \& Former

Dep. Variable:

Smoking Every Day at Interview $=1$

Smoking Every Day or Some Days at Smoking Every Day or Some Days at Interview or Being a Former Smoker=1

Interview $=1$

Smoking-Education Probi

Some or Completed

Post-Secondary

Reduced Form Smoking (Probit)

Reduced Form Education
-0.1855
$(0.0164)$
0.0139

0.0139

$(0.0425)$
$-0.1060$

(0.0126)

0.0134

$(0.0313)$
$-0.1307$

$(0.0130)$

0.0181

(0.0305)

Instrumental Variable Estimates

$\begin{array}{lll}-0.0671 & -0.0334 & -0.0334 \\ (0.0416) & (0.0305) & (0.0305)\end{array}$

Some or Compl. Coll.

$-0.2027$

(0.6246)

$-0.4974$

$(1.0235)$

$-0.5259$

8,363

13,206

13,206

Note. Robust standard errors in parentheses. The instrument consists of a dummy variable for being a male born between 1945 and 1949 .

Covariates include an overall as well as a male-specific quartic in age polynomial, and dummies for gender, marital status, province of residence,

living in a rural area, and family income. Sample excludes the Province of Quebec. 
Table A1. Bivariate Probit Estimates of the Effect of Education on Smoking

Panel A.

(1)

Smoking Regularly vs. Never Smoked

Smoking Regular

(3)

Smoking Every Day or Some Days at

Interview or Being a Former Smoker=1

$\begin{array}{cccc}\begin{array}{c}\text { Self \& Proxy } \\ \text { Respondents }\end{array} & \begin{array}{c}\text { Self-Respondents } \\ \text { Only }\end{array} & \begin{array}{c}\text { Self \& Proxy } \\ \text { Respondents }\end{array} & \begin{array}{c}\text { Self-Responden } \\ \text { Only }\end{array} \\ & & & \\ -0.1203 & -0.1010 & 0.0119 & 0.0475 \\ (0.0181) & (0.0197) & (0.0457) & (0.0507) \\ -0.4951 & -0.4942 & -0.2873 & -0.2961 \\ (0.0166) & (0.0196) & (0.0302) & (0.0319) \\ & & & \\ 147,863 & 121,190 & 197,676 & 163,910\end{array}$

\section{Dep. Variable:}

Non Veteran White Males and Females

Some or Compl. Coll.

B.A.+

N

\section{All White Males and Females}

Some or Compl. Coll.

B.A.+

Non Veteran White Males Only

Some or Compl. Coll.

B.A.+

$\mathrm{N}$
$-0.1311$

(0.0194)

$-0.4206$

(0.0309)

165,925

$-0.1169$

$(0.0444)$

$-0.5171$

$(0.0270)$

60,609
-0.1143
$(0.0219)$

(0.0219)

$-0.4144$

(0.0339)

135,073

$-0.0647$

(0.0505)

$-0.4895$

(0.0410)

44,557
-0.0412
$(0.0504)$

$-0.2455$

227,027

$-0.1285$

$(0.0645)$

$-0.0900$

$(0.1088)$

82,079
$-0.0159$

$(0.0556)$

$-0.2595$

(0.0359)

186,833

Note. Robust standard errors in parentheses. The instrument consists of a dummy variable for being a male born between 1945 and 1950. Covariates include an overall as well as a male-specific quartic in age polynomial, and dummies for gender, marita status, region of residence, living in a metropolitan area, labor force status (dummy for each category), and family income. Average treatment effects are evaluated at the mean value of the regressors while their standard errors are calculated using the delta method. 
(Table A1, continued)

Panel B.

(1)

(2)

Smoking at Interview vs. Never \& Former

Dep. Variable:

Smoking Every Day or Some Days at

Interview $=1$

Self \& Proxy

Respondents

Self-Respondent

Only

Smoking at Interview vs. Former Smokers

Smoking Every Day at Interview==1

Self \& Proxy

Respondents

Self-Respondents

Only

163,910

197,676

$(0.0200)$

$-0.2757$

186,833

227,027

$-0.1127$

-0.1127
$(0.0418)$

$-0.1192$

$(0.0418)$

$-0.3414$

-0.3012
$(0.0952)$

61,537
$-0.1353$

$(0.0840)$

$-0.3727$

84,130

$-0.1049$

(0.0641)

$-0.1715$

$(0.0418)$

102,255

$-0.0695$

(0.0821)

$-0.3315$

(0.0701)

71,073

$-0.0415$

(0.0662)

$-0.1590$

$(0.0440)$

82,427

-0.1492
$(0.1577)$

-0.4546
$(0.0606)$

36,247

$-0.0927$

$(0.1706)$

$-0.4397$

(0.0732)

27,738

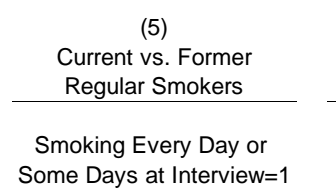

Self-Respondents

Only

$-0.0610$

$(0.0958)$

$-0.1348$

(0.0908)

67,794

$-0.0155$

$(0.0753)$

$-0.0762$

$(0.0484)$

83,014

$-0.1770$

(0.1920)

$-0.2356$

(0.1089)

26,500

Current Regular. vs. Former Regular Smokers

Smoking Every Day

at Interview=1

Self-Respondents

Only

$-0.0615$

(0.0948)

$-0.2917$

(0.0742)

64,811

Note. Robust standard errors in parentheses. The instrument consists of a dummy variable from being a male born between 1945 and 1950. Covariates include an overall as well as a male-specific quartic in age polynomial, and dummies for gender, marital status, region of residence, living in a metropolitan area, labor force status (dummy for each category),

and family income. Average treatment effects are evaluated at the mean value of the regressors while their standard errors are calculated using the delta method. 


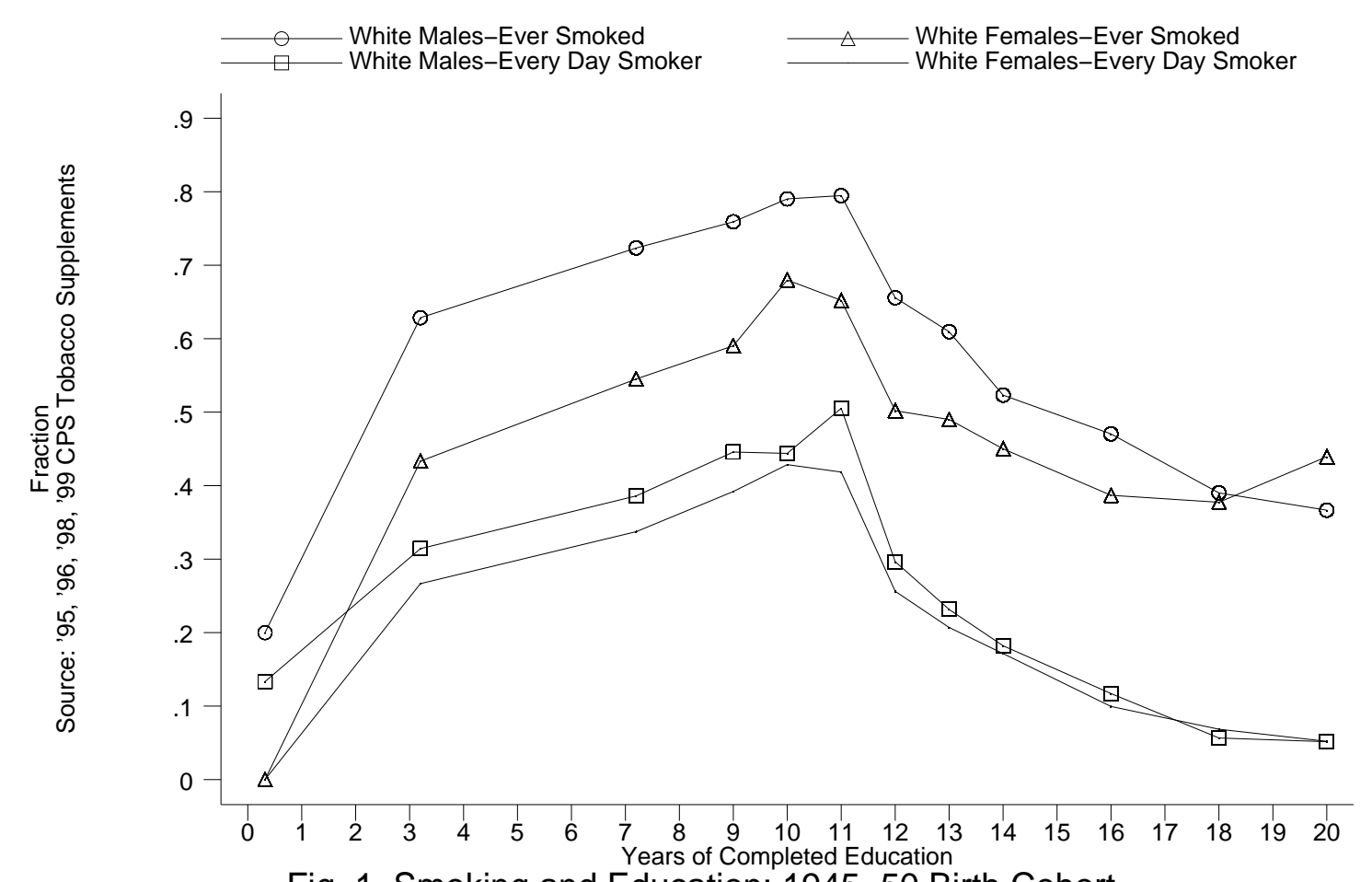

Fig. 1. Smoking and Education: 1945-50 Birth Cohort 


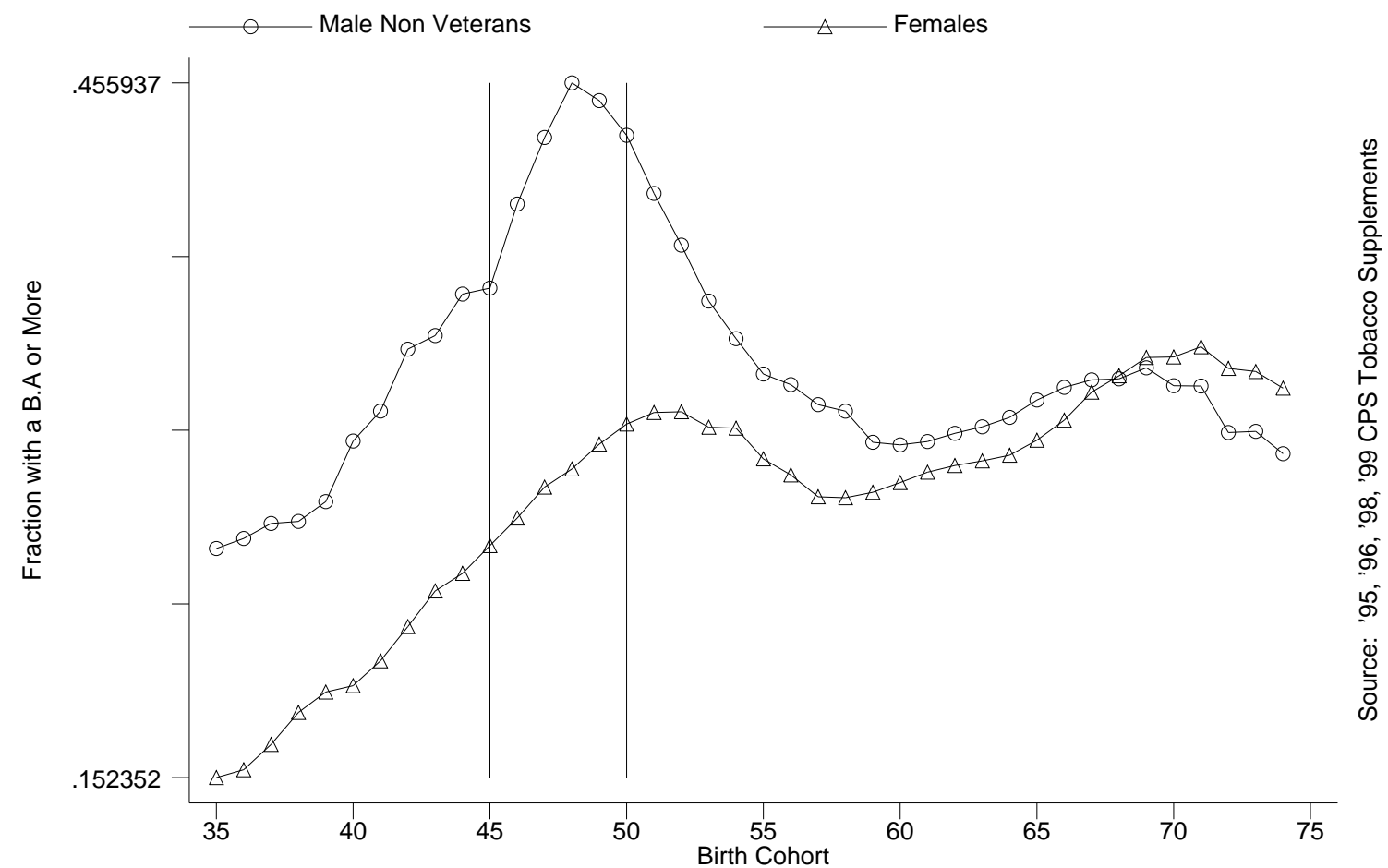

Fig 2a. Educational Attainment-3 Year Moving Average 


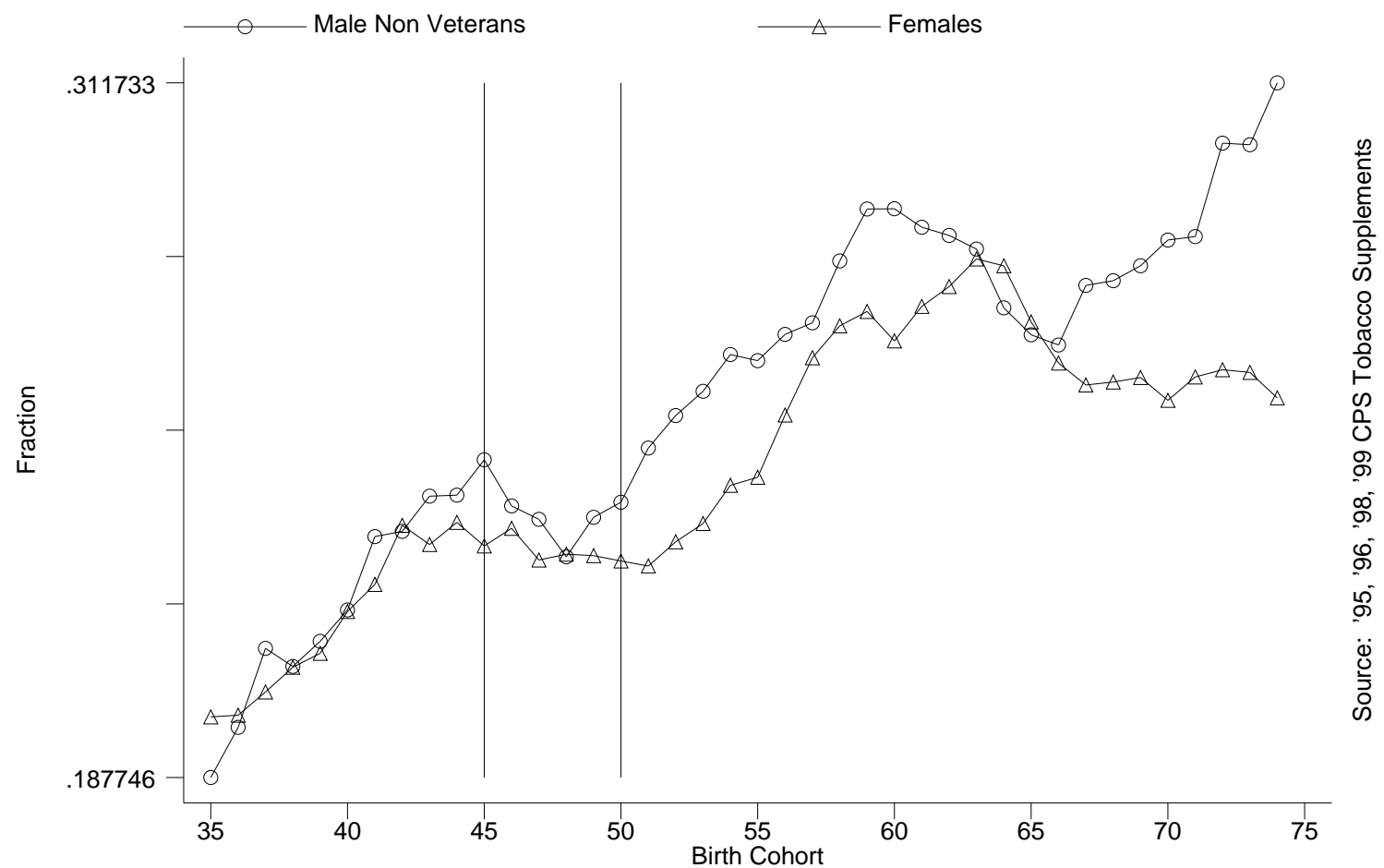

Fig 2b. Smoking Regularly or Occasionally at Interview-3 Year M.A. 


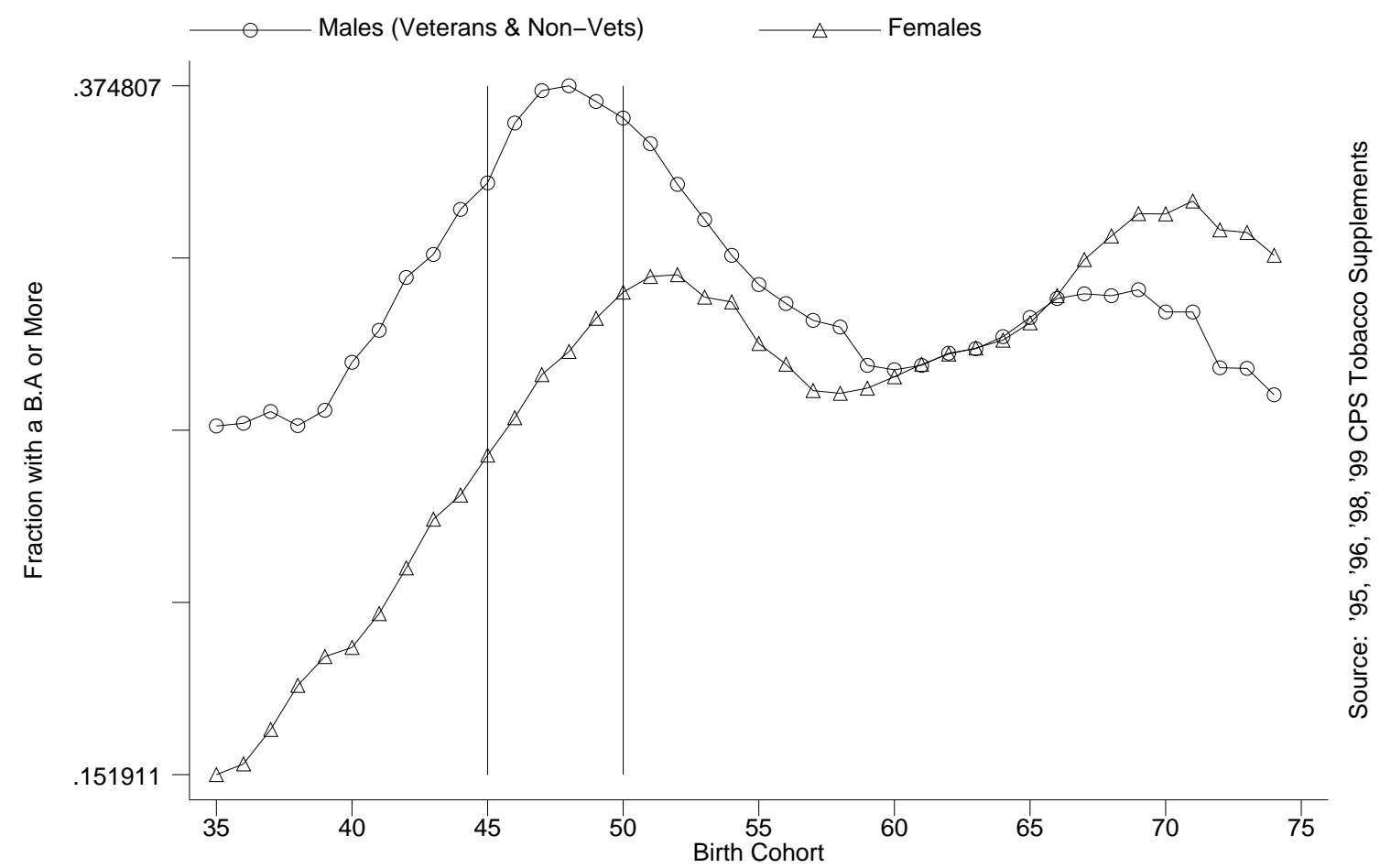

Fig 3a. Educational Attainment-3 Year Moving Average 


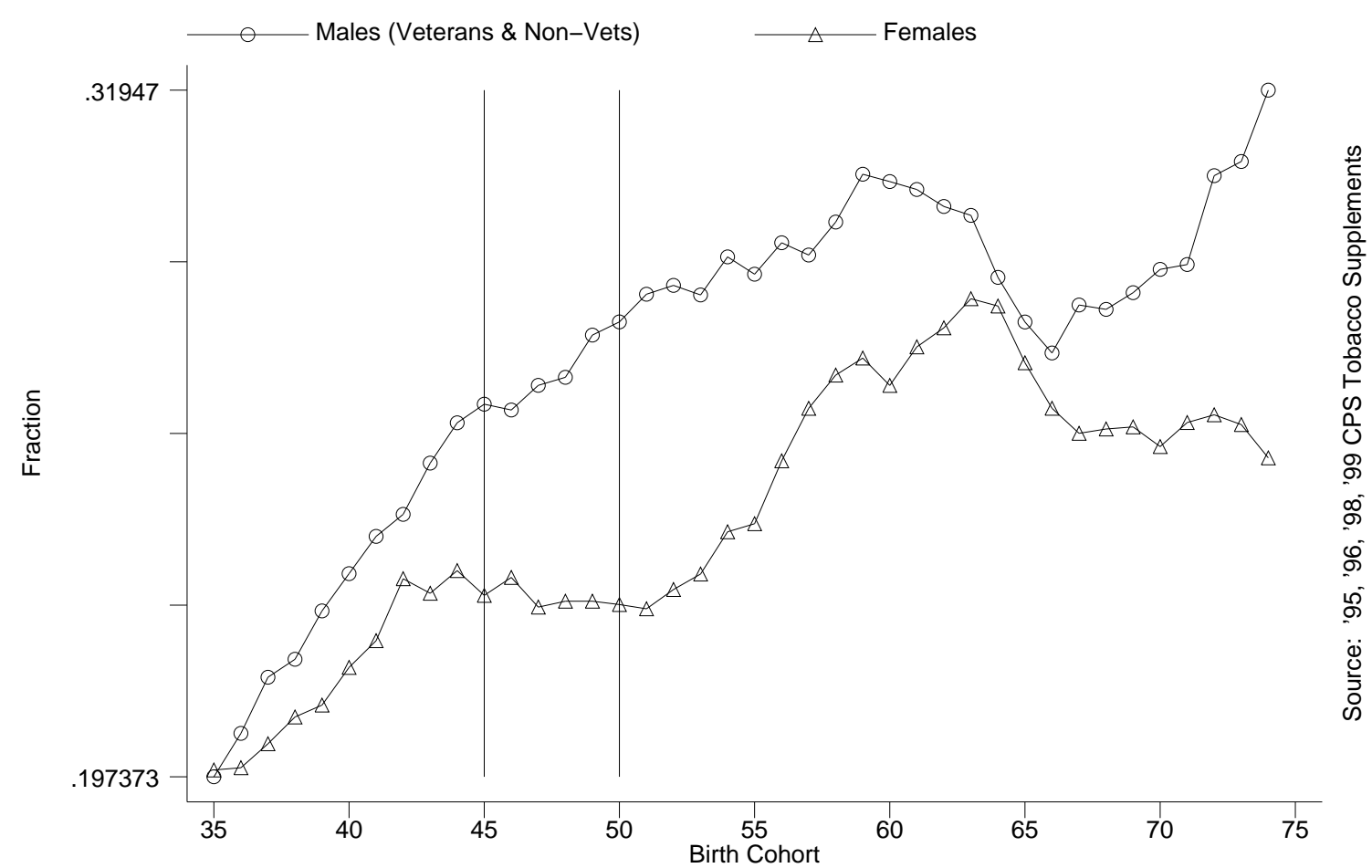

Fig 3b. Smoking Regularly or Occasionally at Interview-3 Year M.A. 


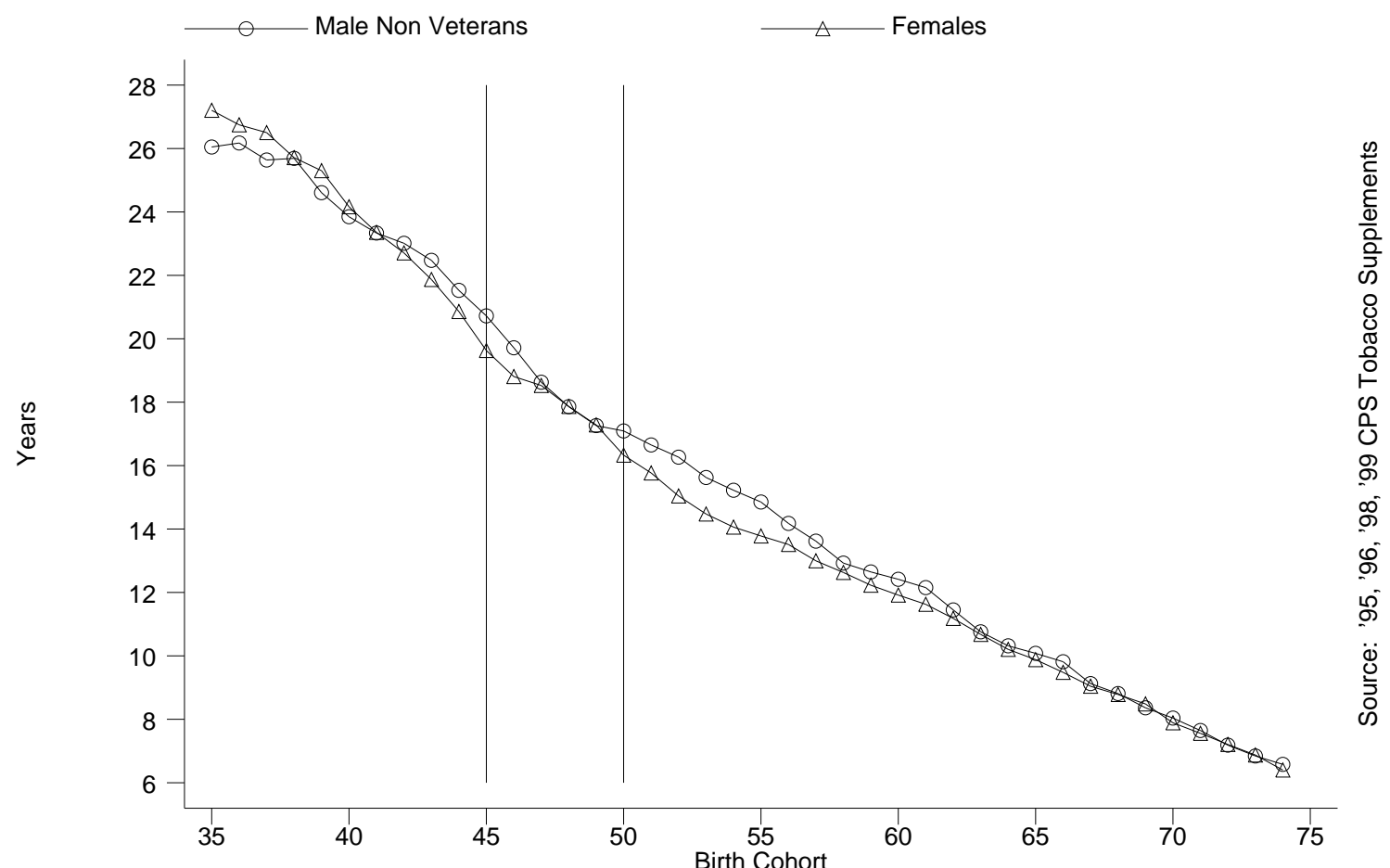

Fig 4. Years Smoking Among Former Regular Smokers-3 Year M.A. 


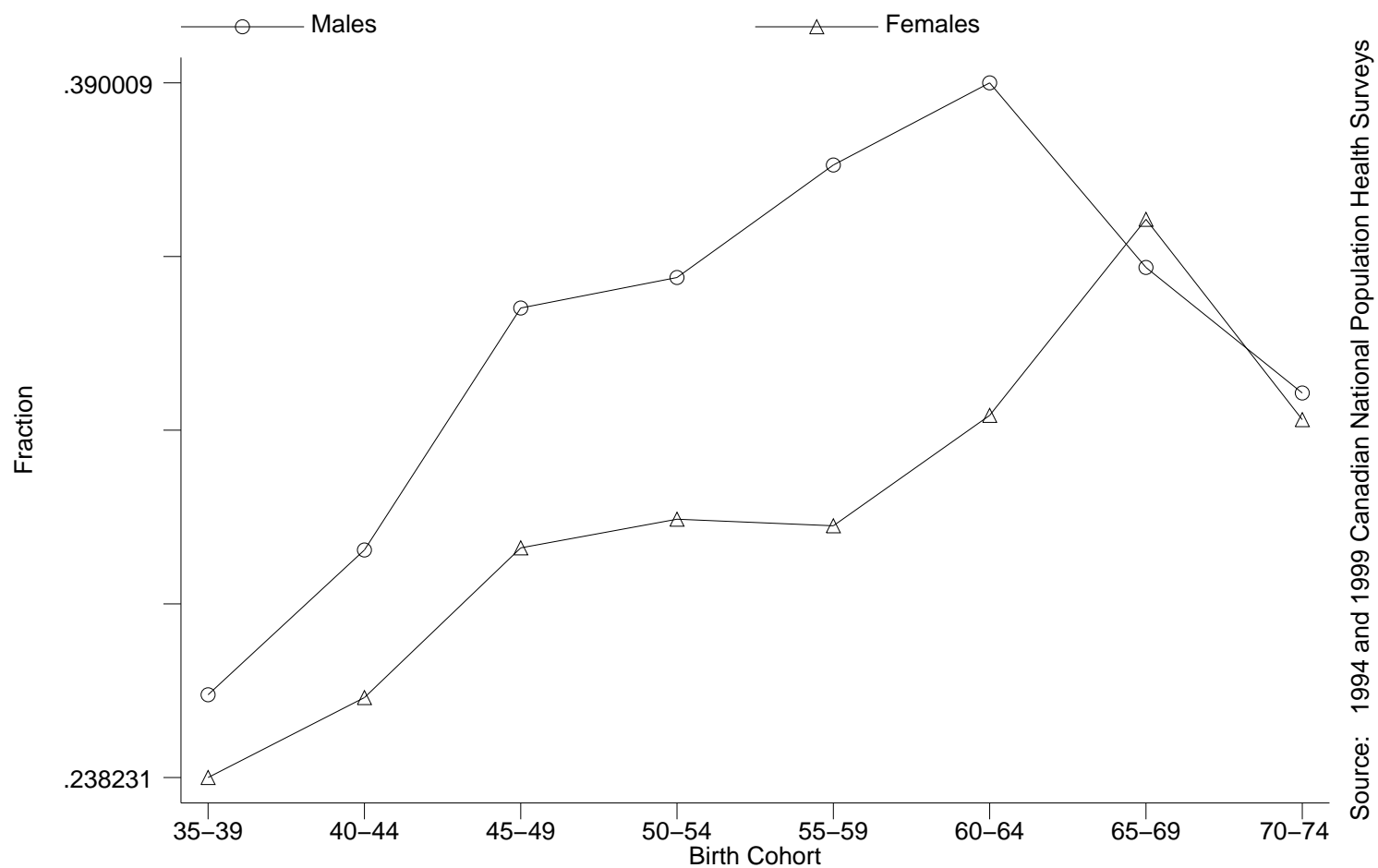

Fig 5. Regular Smokers in Canada 